جامعـة نيويورك أبـوظـبي 世 NYU $\mid$ ABU DHABI

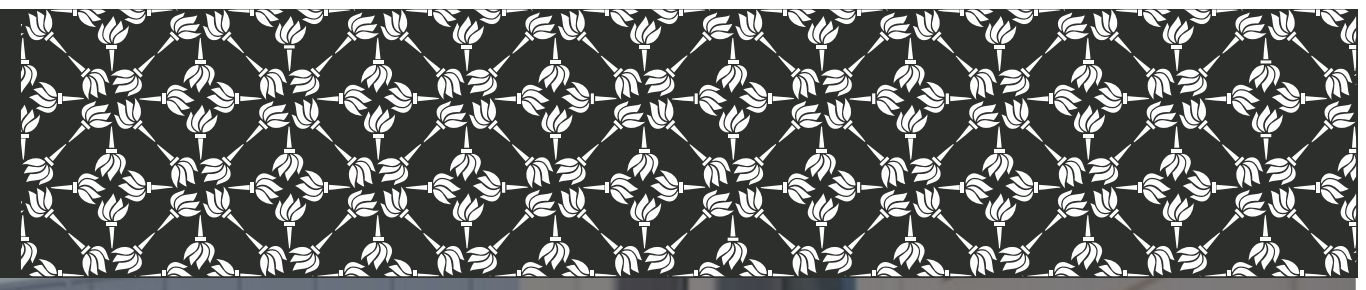

\title{
Majoritarian Bargaining over Budgetary Divisions and Policy
}

\author{
Andrzej Baranski, Nicholas Haas, Rebecca \\ Morton
}

Working Paper \# 0052

July 2020 


\title{
Majoritarian Bargaining over Budgetary Divisions and Policy*
}

\author{
Andrzej Baranski ${ }^{\dagger} \quad$ Nicholas Haas ${ }^{\ddagger} \quad$ Rebecca Morton ${ }^{\S}$
}

July 31,2020

\begin{abstract}
We report the results of a field-in-the-lab experiment in which subjects bargain over a two-dimensional agenda: a donation to a political interest group and the division of a sum of money. We show that subjects sacrifice monetary gains to secure preferred policies and that behaviorally elicited preference intensity correlates with bargaining behavior. We find an ideological majority advantage and a statusquo premium. Minorities benefit most from negotiating on two dimensions because the budgetary division problem allows compromise. Finally, we show that induced preferences over artificial policies fail to capture the bargaining dynamics that arise when real ideological choices are involved.
\end{abstract}

Keywords: legislative bargaining, field-in-the-lab, pork barrel, measurement

*This study received approvals from the relevant Institutional Review Boards. The authors thank Pedro Dal Bó, Sanford Gordon, Aaron Kamm, Dimitri Landa, Alan Wiseman, Sevgi Yuksel, and participants at the Columbia University Conference in Political Economy, the Southern Political Science Association Annual Meeting, the ECPR Advances in the Empirical and Theoretical Study of Parliaments Conference at Konstanz University, and the Washington, D.C. PECO conference for helpful feedback. We are also thankful for the assistance of members of the Ohio State University Experimental Economics Laboratory, and for the research support provided by Mayada Oudah.

$\dagger$ Assistant Professor of Economics, New York University Abu Dhabi. Email: a.baranski@nyu.edu

$¥$ Assistant Professor of Political Science, Aarhus University. Email: nick.haas@ps.au.dk

${ }^{\S}$ Global Network Professor of Politics, New York University NYC and Abu Dhabi. Email: rebecca.morton@nyu.edu 
"Pork barreling, despite its much aligned status, gets things done."

- Evans (2004)

\section{Introduction}

Pork-barrel politics, or the targeting of spending projects to local constituencies in order to secure a legislator's vote, has long been controversial, drawing the ire of journalists and the public alike. However, while the practice has its detractors, ever since it was banned in the U.S. in 2011 many have called for its return, attributing a lack of congressional efficiency to the removal of "grease" from the wheels (Lazarus, 2018). Does the ability to bargain over two dimensions, one ideological and the other budgetary, really "grease the wheels" of the legislative process? Do certain legislators fare better or worse with pork in particular, do majority versus minority party legislators reap different benefits (Evans, 2004)?

Our study aims to extend our understanding of how legislators make choices, a topic that has been the subject of much research, both formal modelling and experimental studies, since the work of Black (1958). ${ }^{1}$ One particularly popular approach is to use multilateral bargaining models as in Baron and Ferejohn (1989). These models typically focus on the distributive aspect of legislative decision-making in which there is a fixed, but divisible, "pie" that is to be divided between the legislators such as discretionary spending or ministries in a newly formed parliamentary government. Yet, many decisions facing legislators involve policies that are not divisible as well as the divisible ones. A number of researchers have attempted to incorporate decisions that involve both non-divisible ideological policy choices and private divisible ones such as in Jackson and Moselle (2002), where the interplay between both dimensions plays a key role in the outcomes that might arise in equilibrium.

Although incorporating ideology in models can be done by modifying the utility function and bargaining space, how to best design an experimental test of the theory is less

\footnotetext{
${ }^{1}$ See Diermeier (2014) for a review of the formal literature and Palfrey (2016) for a review of the experimental literature.
} 
clear. In particular, if we want our experiment to explain naturally-occurring behavior, ideally we would like individuals' valuations of ideological policy choices in the lab to reflect their valuations of policies outside the lab. To that end, and also to increase the salience of decision-making in the laboratory, we would like for decisions in the laboratory to have ideological consequences outside the laboratory beyond subjects' own monetary payoffs. In this paper we present the results of a novel multilateral bargaining experiment in which subjects negotiate the division of a fixed budget and simultaneously make a policy choice, which we operationalize as a donation to a real political interest group.

Prior to the bargaining game, subjects complete a series of incentivized tasks that allow us to identify their preferred policy (e.g., interest group) and the attitudinal strength of their preferences on a series of topics (see Haas and Morton (2018)). Our design seeks to naturally reproduce a setting that allows for a rich pattern of policy and budget compromises to occur as may happen outside the laboratory. In particular, our goal is to understand the bargaining dynamics between political majority and minority members, the role of status quo policies in bargaining outcomes, and how policy choices affect budget sharing. The present study is the first to behaviorally measure ideological position and strength of preferences and investigate how such measures correlate with behavior in a relevant strategic domain.

In our main experimental treatment subjects are placed in triads and information on the ideological preferences of each committee member is publicly revealed. Via majority voting, subjects bargain over a two-dimensional proposal which includes the division of a sum of money and a policy proposal (e.g. which interest group receives a donation). We also investigate treatments with only a budgetary division or only a policy choice to better understand the trade-offs that arise in the combined policy/budget treatment. As a benchmark, we conduct the budgetary division game without political preference information revealed to subjects.

The data support the central equilibrium predictions of our main treatment. First, there is an interaction between political and budgetary compromise: voters are more likely to accept a smaller share of the budget when the proposal implements their favorite policy. 
Compared to a treatment in which members only bargain over a budgetary division, subjects' voting thresholds are significantly lower when policy is also "on the table". However, subjects do not fully exploit their compromise possibilities and typically transfer more than predicted (without gaining much in acceptance odds).

In our experiment, when proposals do not receive a majority vote, the budget vanishes (as in the ultimatum game) and a status quo policy is implemented. In accordance with the theory, we find evidence for a status quo proposal advantage in that members whose preferred policy is the status quo are less likely to propose alternative policies.

Majority members face a double advantage as the theory predicts that they should not compromise on the policy (e.g., they should choose their preferred policy) or budget (e.g., they should not transfer any amount to their partners) dimensions. We find strong evidence for the policy advantage and find that the majority advantage is further exacerbated by majority partners' tendency to share more with each other. Minority members receive a transfer that is on average $30 \%$ less than what majority partners receive. Minority members also compromise on policy more often than predicted, that is, even when it would be cheaper to propose their preferred policy and offer a monetary transfer to the majority member with the weakest preferences.

Our model (and experiment) is one of complete information, and thus, there is no reason for disagreements to occur or differences in acceptance rates across treatments to arise. We find no difference in agreement rates between our main treatment and the policy only and budget only treatments. While one may argue that this result runs counter to the common presumption that a two-dimensional bargaining space greases the wheels of the bargaining process, this is not so, since demands for budgetary shares are much lower compared to the budget only treatment and minority policies are often implemented. Interestingly, when information on ideological preferences is hidden in the budget only treatment, agreement rates drop by 10 percentage points. We argue that knowledge of others' political preferences helps identify coalition partners which may implicitly ease the bargaining process (see Iyengar and Westwood (2015)), even absent the possibility of making a policy choice. 
A natural question to explore is if experiments with induced preferences lead to similar bargaining outcomes compared to a setting with naturally-occurring preferences. To investigate this issue, we conducted a treatment in which policy decisions were conveyed to subjects as where to place a fictitious facility (i.e. a bus stop, as in Christiansen, Georganas and Kagel (2014)) and preferences were induced to match the elicited preferences of previous participants in our main treatment. We find that inducing preferences leads to more aggressive bargaining behavior as reflected by a lower willingness to compromise for non-preferred policies, and that this leads to higher disagreement rates. This result further underscores the efficacy of information on ideological preferences in facilitating the process of coalition formation, which induced preferences over artificial policies cannot mimic.

The paper is structured as follows. In section 2 we present the relevant experimental and theoretical literature on bargaining over policy and budget. We also describe the relevance of our ideological preference elicitation methodology in relation to existing studies. Section 3 presents our theoretical model. Section 4 discusses our main experimental policy and budget bargaining game, within-subject hypotheses, and results. In section 5 we compare behavior in this game with behavior when aspects of the bargaining are changes, specifically when bargaining is only on policy, only on the budget, or when preferences are induced rather than naturally occurring. Section 6 discusses our results.

\section{Literature Review}

\subsection{Bargaining Theory and Experiments}

Our model is a simplified version of the one presented in Jackson and Moselle (2002) in which committee members may bargain repeatedly until an agreement is reached on a policy choice and a budgetary division. The one-round version that we present allows us to compute equilibria in pure strategies (which are generally unique) for each preference distribution and status quo policy. Although a multi-round model is, in principle, richer and more realistic, the one-round model captures similar trade-offs. In particular, the median preference is not always implemented and members with intense policy preferences 
are less likely to be chosen as coalition partners.

To our knowledge, Christiansen, Georganas and Kagel (2014) is the only experimental investigation of Jackson and Moselle (2002). In their study, the authors induced artificial policy preferences by assigning subjects their peak and disutility parameters from alternative policy choices. Subjects were told to imagine that they were choosing where to place a bus stop and that, the further away it was from their preferred location, the higher the walking costs would be. Under their parameterizations, strange bed-fellow coalitions are predicted to occur (i.e. members of opposing bus stop peak preferences form a coalition that does not involve the median player) and are often observed. In their experiment like in ours, committees are comprised of three members and a majority voting rule is in place.

In a related experiment, Delton, DeScioli and Ryan (2018) framed a two-player ultimatum game in the context of a series of political issues on which they had previously surveyed subjects' preferences. Subjects were matched with partners who disagreed with their views on the topic in hand. The allocator's task was described in the instructions as proposing a policy. Policies closer to subjects' political stances earned them more points and less points for the recipient. The authors report a positive correlation between the strength of moral convictions and the policy proposed (i.e. share of money kept). It should be noted that in their study, the choice of policy is hypothetical and merely expressive, as it has no material consequences outside the laboratory. Moreover, it is not possible for subjects to compromise on a second dimension because the budgetary division and policy choice are one single choice. Finally, the game was played between two members as in most ultimatum games (see Roth 1995 for a comprehensive survey).

Our experiment is also related to the experimental investigations of the Baron and Ferejohn (1989) model over the division of a fixed budget. For example, Diermeier and Morton (2005), Fréchette, Kagel and Morelli (2005), and Baranski and Kagel (2015) all report minimum winning coalitions (that is, coalitions formed with the exact number of votes required for passage) to be modal allocations. Laroze, Hugh-Jones and Leininger (2020) investigate behavior in a 3-player majoritarian variant of the game where subjects' 
self-reported ideological stances are publicly revealed (but there are no policy choices to be made, only a budgetary split). The authors find that ideological distance negatively affects sharing, a result we share since majority members typically transfer less to minorities.

Knez and Camerer (1995) extended the ultimatum game to two recipients who make independent acceptance choices and each of whom has different positive outside options. ${ }^{2}$ Our design shares the latter feature in that subjects' outside options are determined by the status quo policy in case of rejection, with the caveat that outside options were negative for some subjects when the status quo did not match their preferred policy. Knez and Camerer (1995) elicited recipients' willingness to accept (WTA) prior to disclosing the proposers' offers, a design feature that we adopted as well. In the treatment where the WTA could not be conditioned on what the other recipient was receiving, they find that the mean WTA is greater than the mean offer, leading to a $45 \%$ rejection rate. $^{3}$

\subsection{Political Preference Elicitation}

A burgeoning literature investigates the consequences of methods of political preference elicitation - in particular, whether preferences are elicited behaviorally as opposed to subjects being asked to state their preferences - on our understandings of political identity and behavior (Chandar and Weyl, 2017; Haas and Morton, 2018; Krosnick et al., 2015; Lalley and Weyl, 2018; Posner and Weyl, 2015; Quarfoot et al., 2017; Weyl, 2017).

Eliciting political preferences behaviorally is posited to overcome three potential shortcomings in stated preference elicitation (Haas and Morton, 2018). First, the low-stakes nature of survey questionnaires make them vulnerable to respondent satisficing, which may account for the high predictive value of stated attitudes about which respondents feel strongly and the comparatively low predictive value of stated attitudes on issues about which respondents care less (Farc and Sagarin, 2009; Holbrook et al., 2016; Krosnick, 1988; Miller et al., 2016; Norris, Krosnick and Visser, 2016; Visser, Krosnick and

\footnotetext{
${ }^{2}$ A few studies have looked at ultimatum games with more than two players. See for example Guth and Van Damme (1998) with one passive (cannot vote) and one active recipient, Okada and Riedl (2005) with efficiency trade-offs, and Casal, Fallucchi and Quercia (2019) in which one of the recipients is an NGO.

${ }^{3}$ In our treatment of a budgetary division without policy information, we find that proposals receive on average 1.1 votes corresponding to $45 \%$ of votes against as well.
} 
Simmons, 2003). A second issue arising from the low stakes attached to stated preference survey questions concerns social desirability bias: where there are no costs or real-world consequences to providing a certain answer, respondents may express a preference or preference strength that they wish they held but truly do not in order to obtain a positive self-image - through self- or virtue-signaling - "on the cheap" (Bodner and Prelec, 2003). Finally, a third issue with survey stated preferences is that individuals' knowledge across the range of topics on which questions are asked is often limited, leading people to "guess" instead of providing firmly-held viewpoints which the surveys are meant to capture (Hill and Tausanovitch, 2015).

Eliciting preferences behaviorally addresses these concerns primarily by increasing the stakes attached to one's answer. Higher stakes should increase the predictive value of answers in the aggregate by making people less likely to satisfice or provide an answer to which they only aspire; further, researchers do not have to rely on the importance that individuals say they attach to an issue, which may or may not be reflected in actual behavior or priorities. Where information is made available so that respondents have the opportunity to make an informed choice, we expect them to make a greater effort to access and absorb the information due to the greater importance they attach to their answer. Finally, to the extent that we seek to explain individuals' real-world behaviors, it is thought that a behavioral measure is a closer approximation.

Our experiment uses a modified version of the behavioral donation method validated by Haas and Morton (2018). Their study compared ideal point estimates for Democrats and Republicans under two methods: a behavioral one where subjects were asked to divide a sum of money between two interest groups on a number of issues and a non-behavioral one where subjects were asked to answer questions on a Likert scale on the same set of issues. They find that Democrats are more likely to be categorized as left-leaning under the behavioral method, especially individuals who are politically engaged, and that wealthy Democrats and male Republicans' ideal points shift to the right of the political spectrum. These departures are potentially consistent with a social desirability story; at the same time, the authors note that the strong correlation with survey results suggests 
that the donation method does not appear to be measuring something entirely distinct, but rather may be reducing the noise in the estimate of the same latent variable.

\section{The Model}

The description and parameters of the game are chosen to match the experimental design, but the game can be easily generalized. We will omit some details of the game described here from the experimental design section to avoid redundancy. We first discuss our main game, the Policy \& Budget game, and then we described the games used in the Additional Treatments presented in Section 5.

\section{Bargaining over Policy and Budgetary Division}

Consider a committee of three members $i \in\{1,2,3\}$ and three possible interest groups to which the committee can make a donation of $\$ 100$. We refer to the donation decision as a policy choice and label each possible choice by its location in the ideological spectrum: left, middle, and right. For notation purposes, let $Y^{j}$ denote a policy $j \in\{L, M, R\}$ and $\hat{Y}_{i}$ denote player $i$ 's preferred policy. We normalize each player's utility derived from their favorite policy to 0 .

The disutility that player $i$ receives from policy $j^{\prime}$ when her peak is at $j$ is denoted by $M A A_{i}^{j \rightarrow j^{\prime}}$. Players derive utility from both policy and money (denoted by $x$ in the formula below) according to the following function:

$$
u_{i}\left(x, Y^{j} \mid \hat{Y}_{i}\right)=\left\{\begin{array}{ccc}
x & \text { if } & Y^{j}=\hat{Y}_{i} \\
x-M A A_{i}^{j \rightarrow j^{\prime}} & \text { if } & Y^{j} \neq \hat{Y}_{i}
\end{array}\right.
$$

The committee makes a two-dimensional choice through voting: dividing $\$ 10$ among themselves and choosing a policy to implement. Each player submits a proposal denoted by $\sigma_{i}\left(t_{i}^{i^{\prime}}, Y_{i}^{j}\right)$ where $t_{i}^{i^{\prime}}$ is a monetary transfer to player $i^{\prime}$ and $Y_{i}^{j}$ is the policy. One proposal is then randomly chosen to be voted over. In equilibrium at most one player receives a transfer so we omit the extra notation where two members may receive transfers.

Prior to the proposal being revealed, all members submit a voting decision vector denoted by $\mathbf{v}_{i}=\left(v_{i}^{L}, v_{i}^{M}, v_{i}^{R}\right)$ in which each entry represents a threshold monetary amount for each policy choice that the player would have to receive in order to approve a proposal 
with that policy choice.

Next, the voting decisions are implemented according to the policy of the chosen proposal. If two or more members are in favor, the proposal is approved and payoffs are realized. If a majority fails to approve the proposal, then the $\$ 10$ vanishes and a default donation is made to an exogenously determined status quo group $\stackrel{\circ}{Y}$. The $M A A$ s of each player, their peak preferences, and the status quo policy are all common knowledge from the start of the game. In the experimental design section we explain how the $M A A \mathrm{~s}$ are elicited.

\section{Bargaining over a Budgetary Division Only}

In this game a proposal consists of $\sigma_{i}\left(t_{i}^{i^{\prime}}\right)$ and a voting decision is a single monetary threshold. There is no policy in place, therefore the utility function is $u_{i}\left(x \mid \hat{Y}_{i}\right)=x$.

\section{Bargaining over Policy Only}

Here, a proposal consists of $\sigma_{i}\left(Y_{i}^{j}\right)$ and a voting decision is a $\mathbf{v}_{i}=\left(v_{i}^{L}, v_{i}^{M}, v_{i}^{R}\right)$ where $v_{i}^{L} \in\{Y e s, N o\}$ for each possible policy. There is no budget to divide, so the utility function is $u_{i}\left(x, Y^{j} \mid \hat{Y}_{i}\right)=0$ when $Y^{j}=\hat{Y}_{i}$ and $u_{i}\left(x, Y^{j} \mid \hat{Y}_{i}\right)=-M A A_{i}^{j \rightarrow j^{\prime}}$ otherwise.

\section{Policy \& Budget Game}

Our principal contribution is our study of how subjects behave when they bargain over policy and budget in the context of naturally occurring policies. In particular, we wish to know the extent that subjects' bargaining behavior over the budget is affected by their preferences over the policy options proposed and the role of majority/minority status. We thus begin our presentation of the experimental design, equilibrium predictions, and the associated experimental results focusing on the Policy \& Budget game (in what we label the Policy \& Budget Treatment) in which we make a number of important withinsubjects' comparisons. In Section 5, we then compare behavior in other treatments in which we vary systematically the features of the game. We describe these treatments in detail in Section 5. 


\subsection{Experimental Design}

Our game consisted of two main parts: (1) an incentivized task for the elicitation of political preferences which allows us to identify $\hat{Y}_{i}$ and $M A A_{i}^{j \rightarrow j^{\prime}}$, and (2) 8 bargaining games. ${ }^{4}$ Subjects were recruited via ORSEE (Greiner, 2015) from an ideologically diverse undergraduate student population at a large U.S. Midwestern university. Participants were offered an $\$ 8$ show-up fee. Sessions lasted between 50 and 60 minutes. Average payments including the show up fee were between $\$ 13$ and $\$ 14$.

\section{Preference elicitation tasks}

Subjects were shown three interest groups who have different political stances on a given topic. For each topic, subjects chose one of the three groups for the experimenter to donate $\$ 1$ on their behalf. This choice allowed us to identify their preferred interest groups. The four topics were welfare, taxes, immigration, and gun control. A brief description was taken from the interest groups' official web pages and displayed to subjects. ${ }^{5}$ The interest groups within each topic were chosen so that they could be ordered on the political spectrum from left to right. ${ }^{6}$

To further ensure that the ordering was common knowledge, we gave subjects a table that displayed the Democrat leaning groups on the left, the ideologically independent groups on the middle, and Republican leaning groups on the right of the spectrum and labelled them as such (see Figure A1 in Section 2.5 in the Supplemental Online Appendix, hereafter Appendix). ${ }^{7}$ After all decisions were made, a randomly chosen donation was implemented for each subject.

Next, subjects revisited each topic and their preferred groups were displayed. They

\footnotetext{
${ }^{4}$ At the beginning of the experiment subjects answered a brief demographic survey, and at the end, there was a short follow-up questionnaire asking subjects about their previous knowledge on the political topics presented in the experiment. All experimental material can be found in the Appendix.

${ }^{5}$ Thus, it is possible for subjects to make an effort to become more informed prior to making a donation decision.

${ }^{6}$ The ordering of groups in the political spectrum also corresponds to the empirical correlation between political orientation and donation decision as evidenced in (Haas and Morton, 2018).

${ }^{7}$ One may argue that in a perfect experiment the chosen interest groups should differ on only one dimension, be equally renowned, and have similar financial composition. We elicit a subject's strength of preference for one group relative to the others and thus we are not making claims in our theory section that the groups are equidistant in the ideological spectrum.
} 
were asked for the minimum acceptable amounts (MAAs) between $\$ 0$ and $\$ 5$ to be given to them so that they would be okay with the experimenter donating $\$ 100$ to each of the alternative interest groups. One subject's decision in each session would be implemented to count for payment and donation. The computer then drew a number in the same interval and, if the chosen MAA was greater than or equal to the drawn number, the donation was made to the alternative group and the chosen subject was paid the drawn number. Otherwise, the subject was paid $\$ 0$ and the $\$ 100$ was donated to their preferred group. This task allows us to identify in an incentivized manner how strongly each subject feels about her preferred interest group. The MAAs can be interpreted as the disutility (money equivalent) from having $\$ 100$ allocated on one's behalf to groups with a different ideological position. See Appendix Section 3 for information on the distribution of preferences and preference strengths by topic area.

During this part of the study subjects were not aware that they would participate in a subsequent bargaining game (although they were aware that there were other parts to the study), as announcing beforehand that such a task would follow could create incentives to strategically misrepresent one's true ideological stance.

In comparison, we extend the elicitation methodology by Haas and Morton (2018) in four key ways. First, we capture individuals' preferences over a greater space: subjects behaviorally express a preference on the ideological spectrum (left, middle, or right). Second, we disentangle preference strength from direction, and we measure it using a continuous measure which allows subjects greater flexibility. Third, we increase the stakes even further by increasing the amount that is potentially donated to an interest group (\$100). Finally, we are able to further evaluate the predictive power of individuals' behavioral decisions on a later decision in an experiment that carries real material consequences and is taken in a strategic domain.

\section{Bargaining Games}

The 8 policy and budget bargaining games proceeded as modeled in Section 3. Subjects were randomly assigned to bargaining committees of three in which they bargained over a budget of $\$ 10$ and which of three interest groups would receive a donation of $\$ 100$. 
Each game started with the computer selecting at random one of the political topics and associated interest groups used in the preference elicitation task above. Each topic was chosen twice, once in periods 1-4 and once in periods 5-8. Each member's elicited preferred group and preference intensity was displayed to all three members in the game. We used a random rematching protocol between games. One committee per session was chosen to count for payment. ${ }^{8}$ We conducted 6 sessions with 15 subjects each for a total of 90 subjects. Our focus is on cases where two members share a policy preference in order to understand the bargaining dynamics between majority and minority members. Because subjects were randomly assigned to committees inevitably some committees had unanimous preferences over policy. That said, $67 \%$ of all randomly formed committees had the desired majority/minority composition.

\subsection{Equilibrium and Experimental Hypotheses in the Policy \& Budget Game}

The bargaining setting that subjects face in our game is essentially a majoritarian ultimatum bargaining game with heterogeneous disagreement values. The heterogeneity in disagreement values stems from the different valuations for the status quo policy that each player may have. Based on our analysis of equilibrium behavior in the game and behavior of subjects in previous bargaining games, we make the following within-subjects' hypotheses concerning bargaining behavior in the Policy \& Budget Treatment.

Hypothesis 1 (Voting Thresholds) Players are willing to accept a smaller share of the budget of the budget when the policy proposed is their preferred one and demand a larger share for alternative policies.

It is important to note that $\mathrm{H} 1$ is based on bargaining behavior in prior experiments in contrast to the game theoretic analysis. As we show, game-theoretic predictions often prescribe that a player should approve any positive share (in order to avoid the implementation of the status quo and receiving no money). However, in the ultimatum game

\footnotetext{
${ }^{8}$ While this choice of compensation is unusual, compensating every person for one randomly selected round would have made our experiment prohibitively costly due to the real donations (and the large donation amounts to create a high-stakes scenario) we are making to interest groups.
} 
experiments subjects typically demand positive shares, thus we argue that the size of the share demanded should be lower when the proposed policies are their preferred ones.

Now we turn our focus to proposal behavior. We expect that a utility-maximizing player will identify the cheapest coalition partner and choose a policy and division of the fund that is just enough to obtain her favorable vote and pass the proposal. The optimal policy and transfer for each player will depend on several factors: (1) whether or not the player is in the ideological majority, (2) the relative strength of her preferences, (3) and the status quo policy. Table 1 summarizes the subgame perfect equilibrium theoretical predictions and a comprehensive analysis is provided in the Appendix Section 1. In the proceeding hypotheses we incorporate qualitative features of these theoretical predictions.

\section{Table 1: Theoretically Predicted Proposals for Policy \& Budget Game}

$$
\text { Status Quo }
$$

\begin{tabular}{lll}
\cline { 2 - 3 } In Majority & Own Preferred Policy & Other Policy \\
\cline { 2 - 3 } & keeps $\$ 10$, proposes own policy & keeps $\$ 10$, proposes own policy
\end{tabular}

In Minority keeps $\$ 10$, proposes own policy depends on relative preferences

Hypothesis 2 (Majority Advantage) For any status quo policy, majority members propose their own preferred policies. If transfers occur, these take place between majority members.

This hypothesis follows from the fact that members are always better off voting in favor of their preferred policy and majority members will always have the required votes to pass such proposals.

Hypothesis 3 (Status Quo Proposer Advantage) Members whose preferred policies are also the status quo propose their preferred policy and a larger share of the budget for themselves.

A member whose preferred policy is implemented in case of rejection should, according to the strict subgame perfect predictions, keep all the budget and propose her own policy. The other members are then indifferent between voting in favor or against and such indifference may be broken with a small transfer. 
Hypothesis 4 (Minorities Compromise) Minority members may compromise on policy by proposing the majority's preferred policy if they have weak policy preferences and there exists a majority member who has strong preferences. Otherwise, minority members propose their preferred policy and a budget compromise by transferring a share to the majority member who cares the least about policy. This applies only when the status quo is not a minority member's preferred policy.

H4 highlights the trade-off between budget and policy compromise that minorities may face. The information on majority members' preferences is key for identifying the cheapest coalition partner.

\subsection{Policy \& Budget Bargaining Results}

We organize the presentation of results around our stated hypotheses. We probe robustness of results and offer additional analyses in Appendix Section 4.

\subsubsection{H1: Policy \& Budget Trade-off}

The empirical prediction of $\mathrm{H} 1$ is that respondents in the Policy \& Budget Treatment should be willing to accept a smaller share of the budget when the policy is their preferred one. We find strong support for this prediction. Figure 1 displays the cumulative distribution functions (CDFs) of subjects' voting thresholds for preferred and non-preferred interest groups. ${ }^{9}$ A Kolmogorov-Smirnov test indicates that the distribution functions are not equal $(\mathrm{p}<0.001) .{ }^{10}$

\footnotetext{
${ }^{9}$ Figure 1 pools across non-preferred interest groups. However, the degree to which subjects viewed different non-preferred interest groups as undesirable varied substantially. See Appendix D.1 for a further breakdown by non-preferred interest group rating.

${ }^{10} \mathrm{In}$ our regression analyses in the appendix we cluster observations at the individual level and we also probe robustness to period and session fixed effects.
} 
Figure 1: Voting Thresholds (Policy \& Budget Treatment)

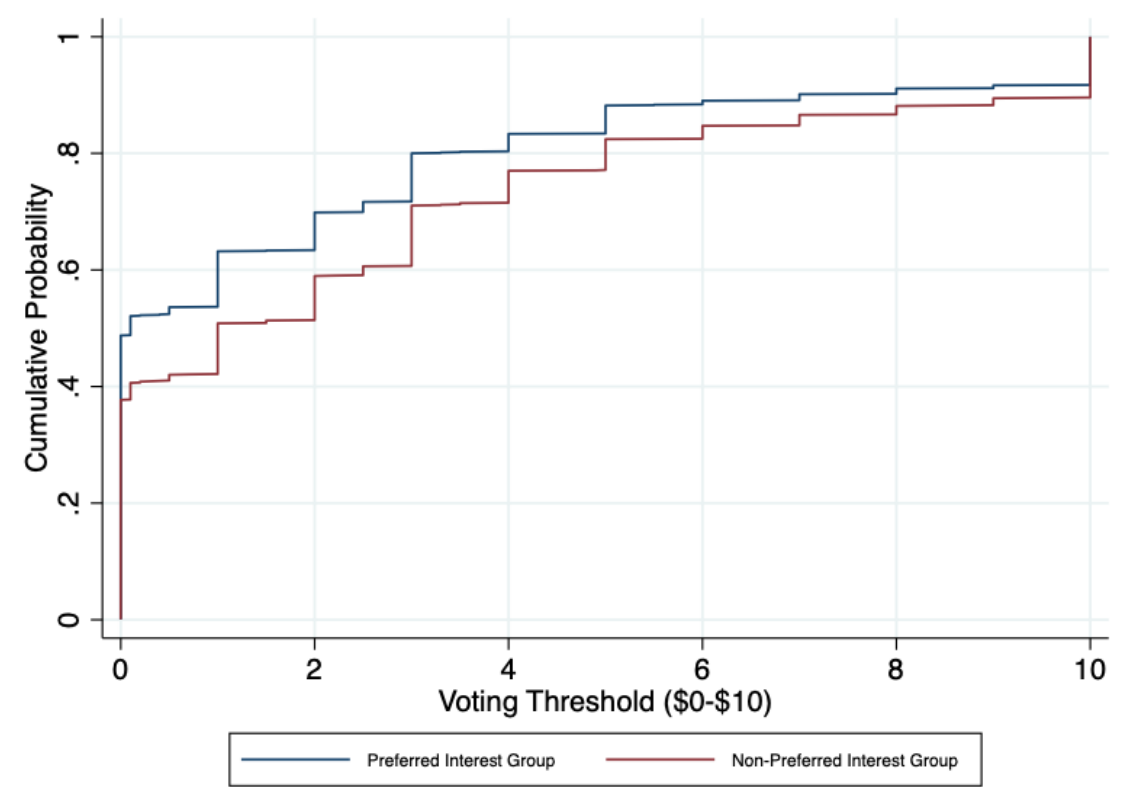

Notes: This figure compares stated voting thresholds for preferred and nonpreferred interest groups for subjects in the Policy \& Budget Game.

\subsubsection{H2: Majority Advantage}

The first empirical prediction of $\mathrm{H} 2$ is that for any status quo donation recipient, majority players will propose their preferred policy and transfer $\$ 0$ to their committee partners. Figure 2 shows that a high percentage of majority players (71\%) - and a significantly higher percentage as compared with minority players (28\%) - choose their preferred policy. 
Figure 2: Policy Choice by Majority/Minority Status and Theoretical Prediction

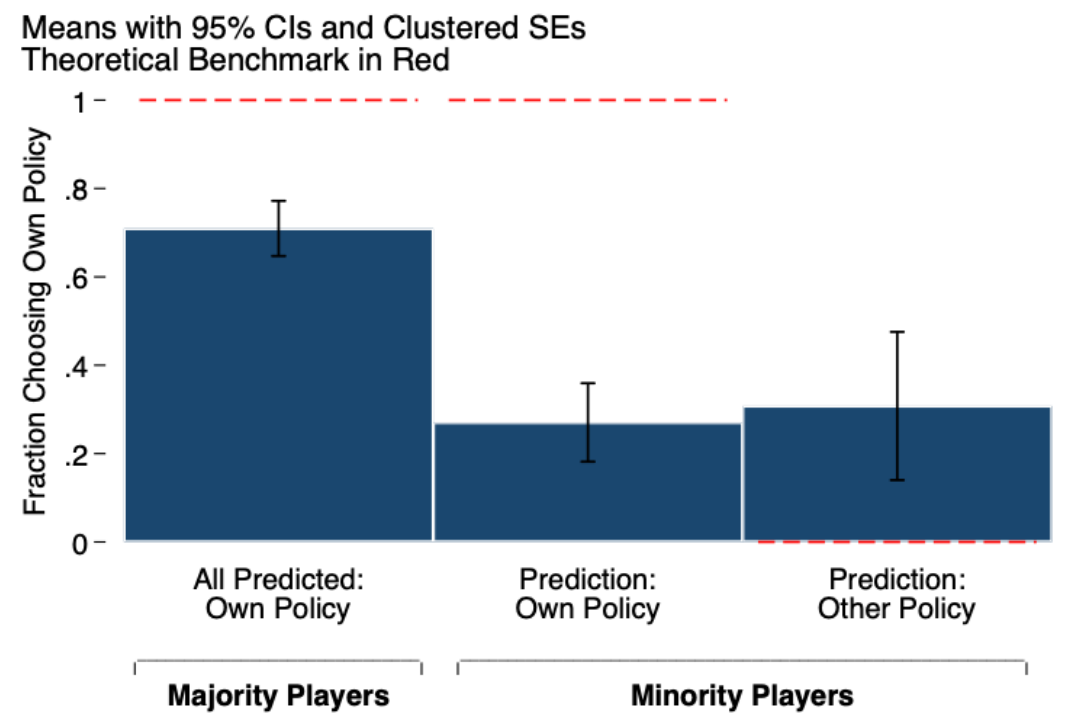

Notes: This figure compares subjects' policy choices (preferred versus nonpreferred policy) by whether they held the majority or minority peak preference and by their theoretically predicted choice. The dashed red lines indicate the theoretical prediction. Standard errors are clustered at the individual level.

Figure 3 takes as its outcome allocation amounts as opposed to policy choice. ${ }^{11}$ We do not find consistent evidence that subjects in the majority allocate to themselves a greater share, and their partners a lesser share, of the budget as compared with subjects holding the committee's minority peak preference. ${ }^{12}$

\footnotetext{
${ }^{11}$ We consider self-allocation amount as opposed to whether one allocated the full $\$ 10$ to themselves (thus indicating a transfer of $\$ 0$ to other players) as our dependent variable because of the limited number of subjects allocating themselves the full $\$ 10$.

${ }^{12}$ Consistent with our expectation, majority players who choose their preferred policy allocate themselves a significantly lesser share of the budget, and their partners a greater share, than majority players who compromise on policy. However, we do not observe similar expected patterns with minority players.
} 
Figure 3: Allocation Amounts by Own and Partner Majority/Minority Status

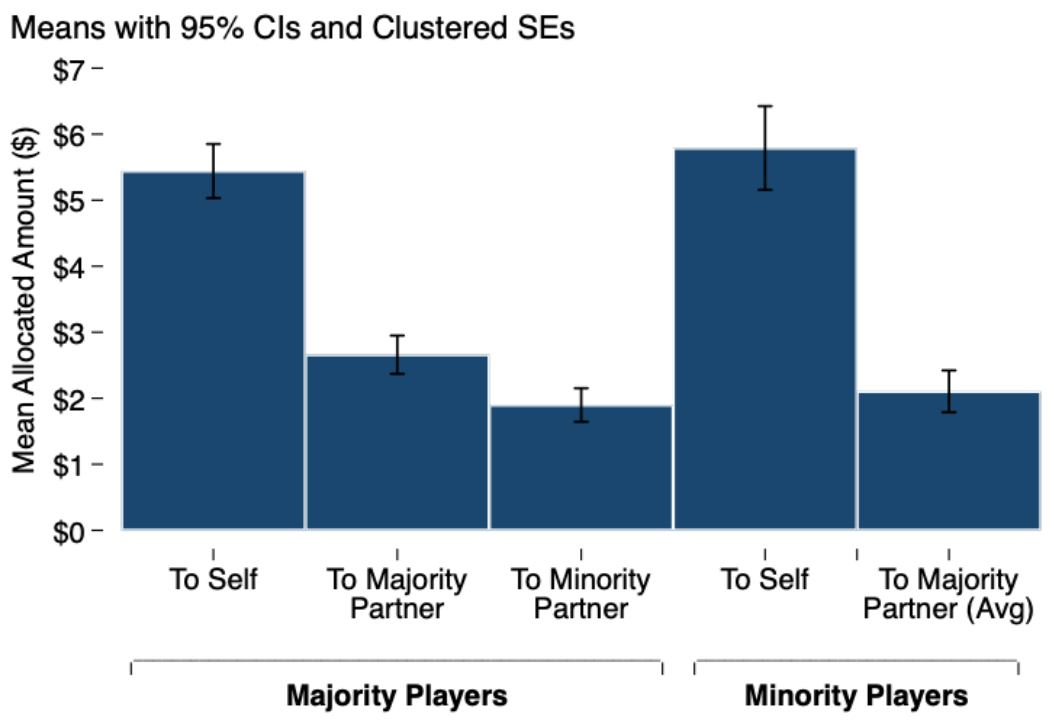

Notes: This figure compares how much of the budget subjects allocated themselves and their partners by whether they and their partners held the majority or minority peak preference. Standard errors are clustered at the individual level.

Majority players transfer a greater portion of the budget to their partners than anticipated. To whom are they transferring the money? The second empirical prediction of H2 is that when transfers take place, majority players should be more likely to transfer funds to other majority players and not to the minority player. Consistent with our expectation, Figure 3 shows that on average majority players transfer a significantly larger portion of the budget to other majority players than to their minority partners.

\subsubsection{H3: Status Quo Proposer Advantage}

H3 posits that the policy choice and amount of the budget that subjects allocate to themselves will be conditional on the status quo policy; when it aligns with their preferred policy, subjects are predicted to propose their preferred policy and a larger share of the budget for themselves. Results presented in Figure 4 support our prediction: subjects are 
more likely to propose their preferred policy when the status quo policy is also their preferred policy. Table A5 in Appendix Section 4.3 reveals that this difference is statistically distinguishable from zero, though it also shows that we do not observe a parallel effect with self-allocated amounts of the budget.

Figure 4: Policy Choice by Status Quo Policy Location

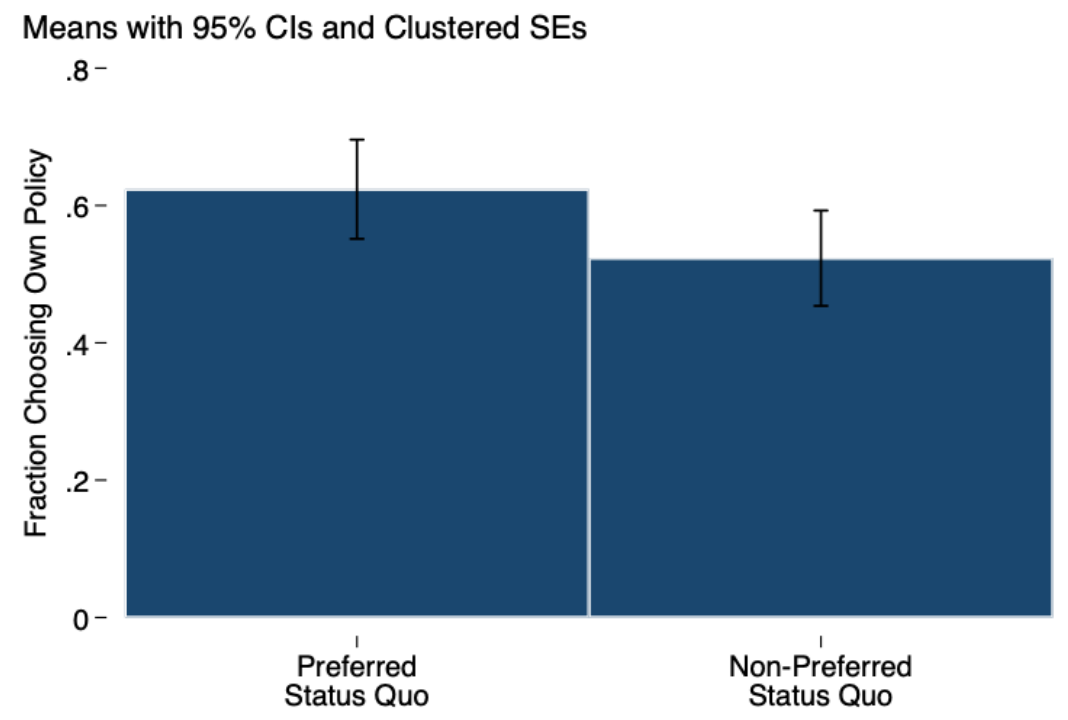

Notes: This figure compares subjects' policy choices (preferred versus nonpreferred policy) by the location of the status quo policy (preferred versus non-preferred). Standard errors are clustered at the individual level.

\subsubsection{H4: Minorities Compromise}

Continuing to H4, our empirical prediction is that minority players' policy choices will depend on whether they have weaker or stronger policy preferences than the majority members. In particular, minority players should propose the majority's preferred policy if there exists a majority player with stronger preferences over policy and if the status quo differs from their own preferred policy (see Table 2). In this case, the minority player is predicted to transfer a share of their budget to the majority player with whom it is cheapest to compromise. Alternatively, the minority player will not compromise on policy. 
We start by pooling all our observations. Minorities choose their own policy only $28 \%$ of the time and the majority's preferred policy $55 \%$ of the time. ${ }^{13}$

In Table 2, we break down our data by theoretical prediction. Minority players propose their own policy only $27 \%$ of the time when they are in a committee in which there exists a majority member with less intense preferences for policy. When theory predicts that minority players should propose the majority policy, they still choose their own $29 \%$ of the time. In either case, minority members choose the majority policy more than half of the time.

\begin{tabular}{llll}
\hline Table 2: Policy Proposal by Minority Members, by Theoretical Prediction \\
\cline { 2 - 4 } & \multicolumn{3}{c}{ Policy Proposal } \\
\cline { 2 - 4 } Should Choose Own Policy & $0.27(.84)$ & $0.56(.95)$ & Other \\
Should Choose Majority Policy & $0.29(.64)$ & $0.54(.83)$ & $0.17(.83)$ \\
\hline
\end{tabular}

Acceptance rates shown in parentheses.

Our results show a tendency for minorities to over-compromise which could be due to the belief that majorities will drive a tougher bargain. While this may be theoretically irrational, it is worth exploring whether or not subjects actually drive a tougher bargain when they are part of the majority. We find that odds of approval rise from $73 \%$ to $89 \%$ when minority members propose the majority's policy instead of their own. ${ }^{14}$ When theory predicts that minorities should propose their own policy, there is a $95 \%$ chance of acceptance if minorities opt for proposing the majority's policy instead, 11 percentage points higher than if they had followed the prediction (84\%). Minorities face the lowest odds of acceptance (64\%) when they are predicted to choose the majority policy but choose their own policy instead. In this case, following the prediction leads to a $83 \%$ chance of approval.

In summary, we find significant support for all four of our empirical hypotheses: 1) players accept a smaller share of the budget when the proposed policy is their preferred one

\footnotetext{
${ }^{13}$ In cases where the majority and minority players are at the extremes of the spectrum, we find that $22 \%$ of the time minority players propose a middle ground.

${ }^{14}$ In contrast, majority members face lower approval odds when proposing the minority player's preferred policy, as the agreement rate drops from $91 \%$ to $87 \%$.
} 
and demand a larger share for alternative policies; 2) majority players generally propose their preferred policy and propose transfers to other majority players; 3) if a player's preferred policy is the status quo, they propose it; and 4) minorities compromise when predicted. That said, a number of our results are unexpected and contrary to predictions. In particular, we find majority players keep less of the budget for themselves and transfer more than predicted. We further find that minorities compromise more than predicted, in particular, when the status quo is their preferred policy and they should choose it, they often compromise.

\section{Additional Treatments and the Importance of Ide- ology}

The Policy \& Budget game we explore above has a number of features that make it distinctive from a simple multilateral bargaining game. Not only do subjects bargain over both policy and budget, but they also learn about the policy preferences of the other players in the game. We use naturally occurring preferences rather than induced preferences as is standard in such games. In this section we explore each of these features in detail and the extent that they matter in explaining the behavior we observe. We conducted three different versions of the game: Budget Only, Policy Only, and Induced Policy \& Budget. In the Budget Only games subjects bargained over the $\$ 10$ without any contributions to interest groups. We conducted two versions of the Budget Only game, one in which subjects were given the same preference information about each other as in the Policy \& Budget game (Budget Only) and one in which no ideological information was shared (Budget Only No Information). In the Policy Only game the subjects bargained only over policy and no budget was divided. In the Induced Policy \& Budget game we assigned subjects ideological positions as we describe in more detail below. We first describe our experimental design and hypotheses concerning how we expect behavior in these games to compare to behavior in the Policy \& Budget game and then our experimental results. Table 3 summarizes these additional treatments: 


\begin{tabular}{lcccccc}
\hline \multicolumn{7}{c}{ Table 3: } \\
\hline Treatment & Policy & Budget & Infor & Preferences & Sessions & Subjects \\
\hline Budget Only & No & Yes & Yes & Behavioral & 6 & 87 \\
Budget Only No Information & No & Yes & No & Behavioral & 3 & 45 \\
Policy Only & Yes & No & Yes & Behavioral & 3 & 48 \\
Induced Policy \& Budget & Yes & Yes & Yes & Induced & 4 & 69 \\
\hline
\end{tabular}

The Budget Only Treatments and the Policy Only Treatment followed the same overall design as the Policy \& Budget Treatment. That is, all subjects participated first in the incentivized task to elicit their political preferences, played 8 bargaining games with random rematching between games, and then answered the follow-up questionnaire. The bargaining games in these three treatments differed as described in Table 3 above.

In the Induced Policy \& Budget Treatment subjects did not complete the political preference elicitation task before bargaining. Instead they were assigned the preferences obtained from previous participants in the Policy \& Budget Treatment without political labels. Specifically, the policy component of the game was similar to that used in Christiansen, Georganas and Kagel (2014). That is, in the policy portion of the bargaining the players bargained over where to locate a given facility with three location options: left, middle, right. Each was assigned a personal location and were paid according to how close the chosen location was to their personal location as if they had the elicited preferences of a previous subject in the Policy \& Budget Treatment. The bargaining games proceeded in this fashion. Payoffs from policy were similar to that used in Christiansen et al (2014) in terms of losses for deviations from subjects' induced ideal policies. The instructions for this treatment with details on how payoffs were explained to subjects are presented in the Appendix Section 2.4.

\subsection{Hypotheses Comparing Behavior Across Treatments}

Hypothesis 5 (Trade-offs and Policy Compromise) Minorities compromise significantly less in the Policy Only Treatment than in the Policy 8 Budget Treatment.

Minorities members can compromise on policy by accepting budgetary transfers in the Policy \& Budget Treatment, as we found above. However, in the Policy Only Treatment 
such trade-offs do not exist. Hence, we expect that minorities will have little incentive to compromise and that there will be significantly less compromising behavior.

Hypothesis 6 (Voting Thresholds Between Treatments) Overall, the distribution of voting thresholds in the Policy $\&$ Budget Treatment is skewed to the left and significantly lower on average compared to the voting thresholds in the Budget Only Treatments.

In the Policy \& Budget Treatment, the theory predicts that a player is willing to accept a $\$ 0$ share when her preferred policy $j$ has been proposed and that she must be compensated with a positive transfer when the policy proposed is $j^{\prime}$. Such a transfer makes the player indifferent between accepting the proposal and the outside option. ${ }^{15}$

According to the subgame perfect Nash equilibrium, players in the Budget Only Treatments should accept any positive transfer (indifferent at $\$ 0$ ). However, the previous literature shows that subjects rarely accept such highly unequal divisions. Thus, given the impossibility of compromising on policy in the Budget Only Treatments, we expect voting thresholds to be larger on average.

Hypothesis 7 (One-way Splits and Minimum Winning Coalitions) One-way splits of the budget will arise only when subjects can bargain over both dimensions. The modal budgetary split division are two-way splits.

Vast empirical evidence shows that subjects rarely vote in favor of low monetary offers in ultimatum games. However, in the Policy \& Budget Treatment, members may compromise on policy and keep the full budget which could potentially count with a favorable vote from the recipient of the policy, requiring no transfer at all. This is not possible in the Budget Only Treatments.

We expect positive transfers for the formation of minimum winning coalitions to be the modal split of the fund as has been in related three-player, majority rule, bargaining experiments (Palfrey, 2016). It is worth noting that our voting procedure is such that

\footnotetext{
${ }^{15}$ The transfer is calculated with respect to the status quo. If the proposed policy is closer to the player's peak than the status quo, then there is no transfer because the utility from the current proposal is greater than the outside option which entails a favorable vote.
} 
only one's minimum share is elicited, and thus, expressing preferences for others' shares is virtually impossible at this stage so we expect few grand coalitions.

Hypothesis 8 (Agreement Rates) There are no differences in agreement rates between Treatments.

In all our treatments, players' utilities are common knowledge. According to the equilibrium predictions, there is no scope for disagreement between players in any of our treatments: each subject should compute the optimal offer that will be accepted. This theoretical prediction runs contrary to the presumption that subjects will find it easier to reach an agreement when both policy and budget are on the table because of the possibility to compromise compared to one-dimensional bargaining. Note, however that even if we find evidence in line with H6, that subjects have lower voting thresholds in the Policy and Budget Treatment compared to the Budget Only treatments, we cannot unequivocally conclude that agreement rates will be higher because subjects will likely adjust proposals in response to the expected voting thresholds.

With respect to the role of information on policy preferences in the Budget Only Treatments, it is not clear what the overall effect on agreement rates will be. For example, if two members of a committee share a policy preference and this is known to them, such information can be a natural focal point for whom to share the budget with. However, minority members may anticipate this in-group bias and react by stating lower voting thresholds which would make them more attractive coalition partners. Thus, we take the game-theoretic prediction of no difference at face value as our hypothesis.

We now turn to hypotheses that concern comparisons in behavior when preferences are behaviorally elicited versus when they are induced. We posit two main hypotheses, one regarding the relationship between elicited preferences and bargaining behavior, and the other comparing bargaining behavior under elicited and induced preferences.

\section{Hypothesis 9 (Correlation Between Elicited Preferences and Voting Thresholds)}

The behaviorally elicited preferences correlate positively with voting thresholds. 


\section{Hypothesis 10 (Voting Thresholds with Elicited and Induced Preferences) Induced}

and Elicited preferences lead to the same voting thresholds on average.

Should we expect subjects' voting thresholds to be higher or lower when preferences are induced? On the one hand, thresholds might be lower if inducing preferences over artificial policy choices does not instill the same sense of intensity over policy, as subjects do not find that such decisions have consequences outside the laboratory. Another reason could be that political ideology may be an important component of some subjects' identities which becomes more salient when subjects are placed in triads (as opposed to the induced task where no comparison group exists). As such, subjects in the naturally-occurring ideologies Policy \& Budget Treatment may feel more compelled to defend their preferred policy and raise their voting thresholds. In the terminology of Akerlof and Kranton (2000), compromising on policy may carry an identity cost beyond the individual preference cost for alternative policies.

On the other hand, one might hypothesize that voting thresholds will be higher using induced preferences because in the Policy \& Budget Treatment subjects' only source of material payoffs stems from agreeing on a proposal and receiving the established shares of the budget and thus they should be more willing to accept small amounts of the budget. Another possibility is that real world consequences will moderate these subjects, who will state lower thresholds than Induced Policy \& Budget subjects because they view a realworld donation as having a positive effect on the world, even if it goes to a non-preferred interest group. A final possibility suggested by prospect theory (Tversky and Kahneman, 1992) is that because policy decisions in the Induced Policy \& Budget Treatment are framed in the loss domain, i.e. how much money one will lose from each alternative policy implementation, subjects will engage in risk loving behavior (i.e. higher willingness to take the risk of disagreement), which would be reflected in higher voting thresholds for non-preferred policy locations.

In light of the lack of previous evidence that could inform our conjectures, we pose our hypothesis in a way that reflects the exploratory nature of our work. 


\subsection{Results with Additional Treatments}

\subsubsection{H5: Budget Trade-offs and Compromise}

A comparison between policy proposals in the Policy \& Budget Treatment and the Policy Only Treatment demonstrates that the possibility of a budgetary transfer affects policy compromises. We find that subjects in the Policy Only Treatment propose their own policy almost $80 \%$ of the time, representing an approximate $23 \%$ difference across treatments relative to majority members (see Figure 5 and Table A6 in Appendix Section 4.4). Figure 5 shows that this effect is mainly driven by the minority player's inability to compromise in the Policy Only Treatment.

Figure 5: The Effects of Budget Bargaining on Policy Choice

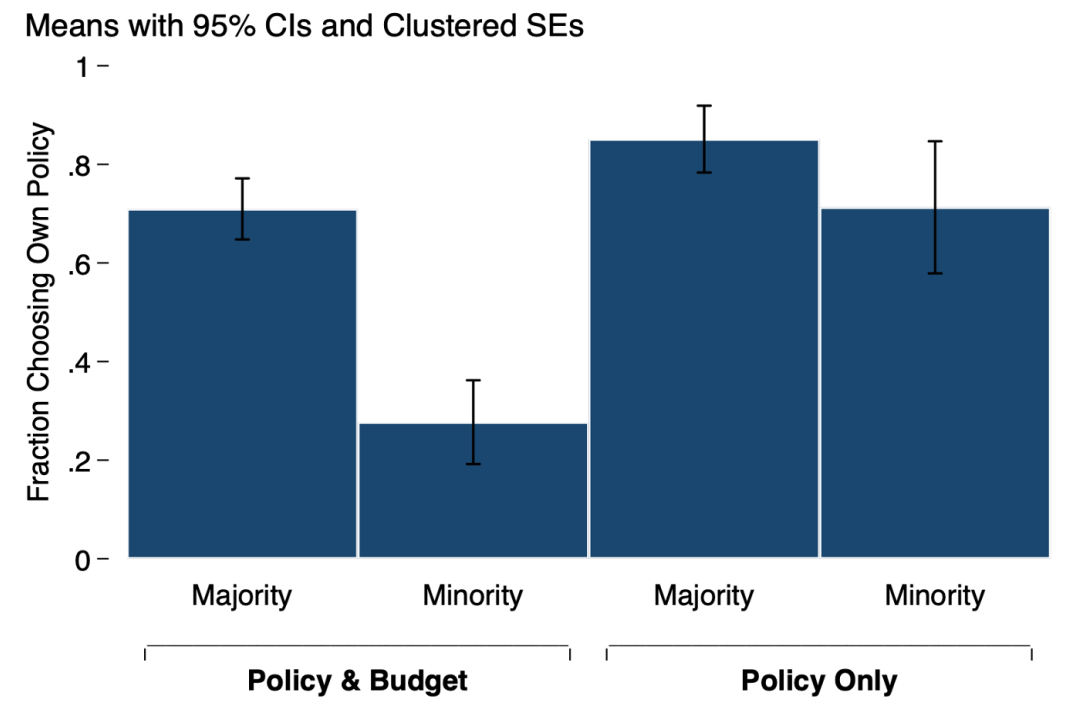

Notes: This figure compares subjects' policy choices (preferred versus nonpreferred policy) by whether they held the majority or minority peak preference and by whether they were in Policy \& Budget Treatment or Policy Only Treatment. Standard errors are clustered at the individual level. 


\subsubsection{H6: Voting Thresholds Between Treatments}

The empirical prediction of $\mathrm{H} 6$ is that the voting thresholds in the Policy \& Budget Treatment will be left-skewed and significantly lower on average as compared with the Budget Only Treatments. Figure 6 provides support for this supposition: There is a higher proportion of low voting thresholds in the former compared to the latter. KolmogorovSmirnov tests indicate that the distribution function of voting thresholds for the former is significantly different from the distribution functions for both Budget Only Treatments ( $p<0.001$ for both comparisons). The CDFs for the Budget Only Treatments jump at a voting threshold of $\$ 3$, indicating that when respondents only negotiate over a budget they are more likely to ask for a share that would result in an equal split between their partners and themselves.

Figure 6: The Effects of Policy on Voting Thresholds

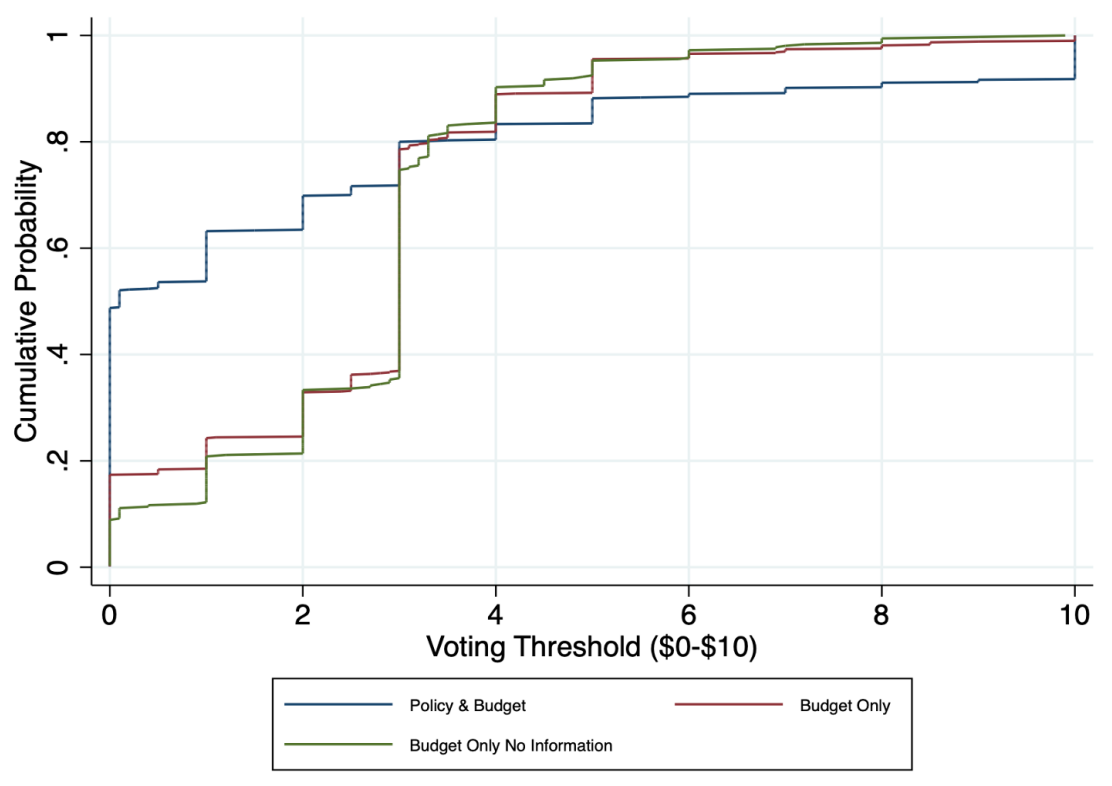

Notes: This figure compares stated voting thresholds for subjects in the Policy \& Budget Treatment and the Budget Only Treatments. In the Budget Only Treatments, subjects stated thresholds for a budget division only; we compare thresholds in those to subjects' thresholds for preferred interest groups in those treatments to those in the Policy \& Budget Treatment. 
Table A7 in Appendix Section 4.5 shows that voting thresholds are on average higher in the Budget Only Treatments than the Policy \& Budget Treatment. In sum, we thus find support for H6.

\subsubsection{H7: One-way Splits, Minimum Winning Coalitions}

As shown in Figure 7, one-way splits constitute $20 \%$ of all proposals in the Policy \& Budget Treatment as compared with only 6\% (Budget Only) and 8.9\% (Budget Only No Information) (see Table A8 in Appendix Section 4.6 for regression analysis). There are virtually no approved one-way splits in the Budget Only Treatments (less than 3\% of accepted proposals) while these splits represent $15 \%$ of approved proposals in the Policy \& Budget Treatment. This pattern is consistent with findings supporting H1 and H6, in particular, the result that a greater percentage of subjects in the Policy \& Budget Treatment is willing to accept a zero share of the budget when the policy proposed is their preferred one.

Figure 7: Policy and One-way Splits

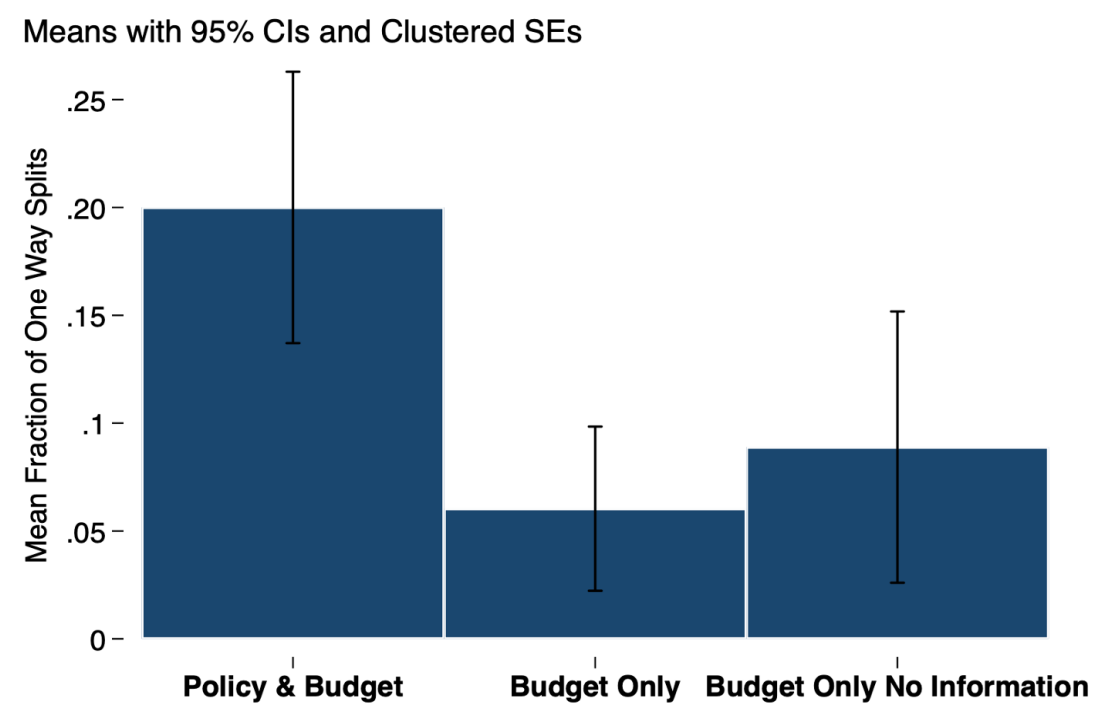

Notes: This figure compares subjects' likelihood of proposing one-way splits in the Policy \& Budget, Budget Only and Budget Only No Information Treatments. Standard errors are clustered at the individual level. 


\subsubsection{H8: Agreement Rates}

In the treatments with revealed behavioral preference information (Policy \& Budget, Policy Only, and Budget Only), 86\% of proposals are accepted with no significant difference between treatments. In the Budget Only No Information and the Induced Policy \& Budget Treatments, agreement rates significantly drop to 78\% (see Table A9 in Appendix Section 4.7). These differences indicate that revealing information on behaviorally measured political preferences helps grease the wheels of bargaining even absent policy decisions. Consistent with findings reported in Figure 5 showing that minorities compromise more on policy where two dimensions exist, agreement rates indicate that minority players benefit the most from coupled bargaining: their odds of approval rise from $66 \%$ in the Policy Only to $83 \%$ in the Policy \& Budget Treatment (from $90.5 \%$ to $98.4 \%$ for majority members).

\subsubsection{H9: Correlation Between Elicited Preferences and Voting Behavior}

H9 predicts that behaviorally elicited preferences would correlate positively with behavior in the bargaining game, though it remains neutral as to whether the correlation would be stronger or weaker as compared with induced preferences. Figure 8 offers support for this hypothesis: we find that behaviorally elicited MAAs are positively correlated with subjects' voting thresholds in the bargaining game. We also document a positive correlation between induced preferences and behavior in the bargaining game. Figure A7 in Appendix Section 4.8, which compares our behavioral measure to stated partisan preferences and ideologies, further indicates that our behaviorally elicited measure is capturing real political preferences and provides suggestive evidence that this method may help us to better distinguish between "strong" and "weak" partisans than do typical non-behavioral

survey instruments. Finally, we present additional evidence attesting to the relationship between MAAs and voting thresholds in the Appendix Section 4.1. 
Figure 8: Elicited Preferences and Voting Thresholds

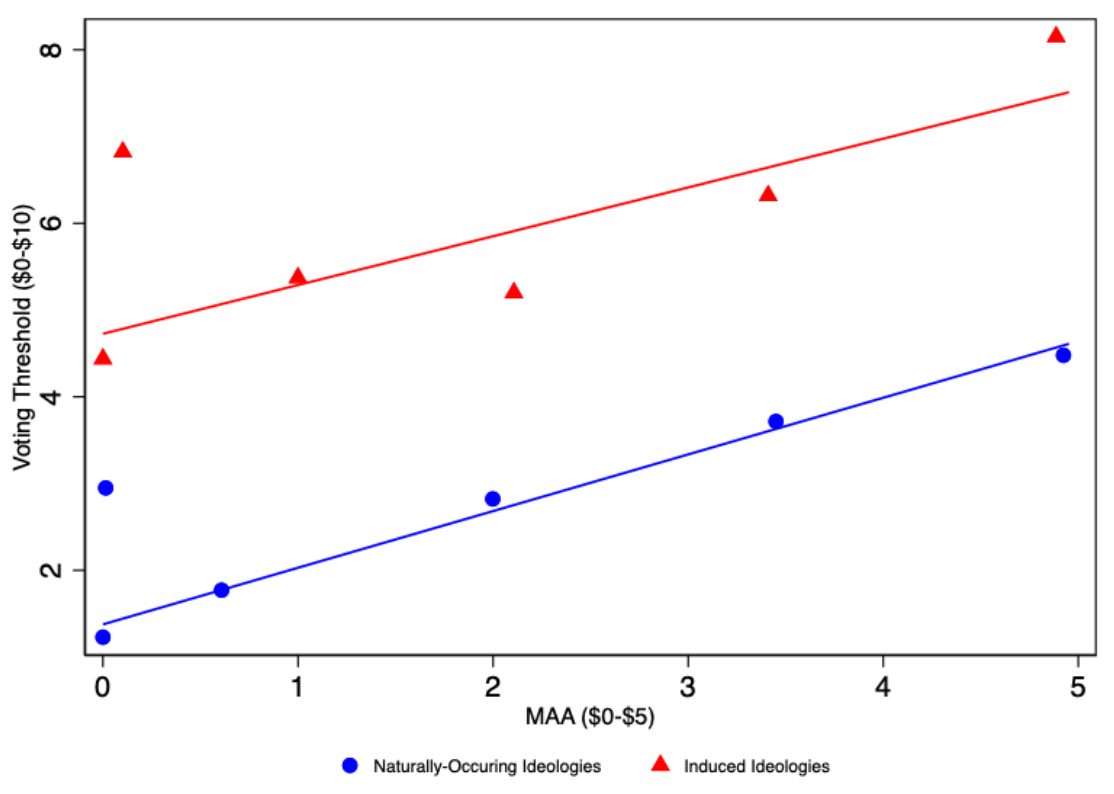

Notes: This figure displays the relationship between stated minimum acceptable amounts and voting thresholds in the Policy \& Budget Treatment and the Induced Policy \& Budget Treatment. Observations are binned to ease interpretation. Analysis controls for period and session fixed effects.

\subsubsection{H10: Induced vs. Elicited Preferences}

H10 predicted that voting thresholds would not differ in a predictable way under induced versus elicited preferences. However, as Figure 9 illustrates, there are clear differences in voting thresholds between the Policy \& Budget and Induced Policy \& Budget Treatments. Specifically, the data show that subjects demand larger shares on average when preferences over policy are induced. This difference is driven by the thresholds for nonpreferred policies being higher (Kolmogorov-Smirnov test: $\mathrm{p}<0.001$ ), as we find that thresholds in both treatments are virtually identical when the policy proposal is one's peak (Kolmogorov-Smirnov test: $\mathrm{p}=0.65$ ). 
Figure 9: Behavioral vs. Induced Preferences and Cumulative Distributions of Voting Thresholds

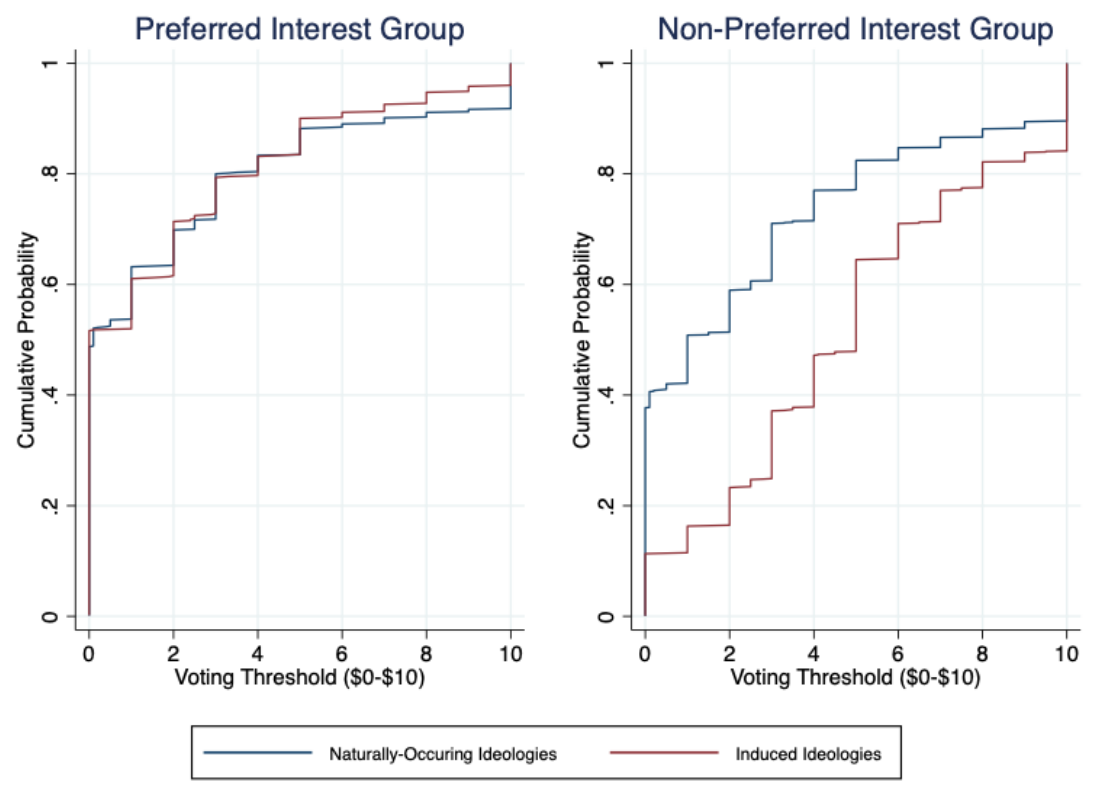

Notes: This figure compares stated voting thresholds for preferred and nonpreferred interest groups for subjects in the Policy \& Budget Treatment with the Induced Policy \& Budget Treatment.

One interpretation consistent with results is that differences in thresholds are explained by prospect theory (Tversky and Kahneman, 1992), as detailed in Section 5.1. Subjects may be more willing to incur a risk of disagreement (by raising their thresholds) when policy choices are framed as losses from deviating from one's preferred location as compared with the donation choice. If subjects effectively perceive voting thresholds in the Induced Policy \& Budget Treatment as inducing a risky prospect over losses and, instead, a risky prospect over gains in the Policy \& Budget Treatment, then the observed behavior is consistent with prospect theory. The equality of thresholds for the preferred policy further supports this conjecture as both decisions are being evaluated in a non-negative domain. A comparison of Figures A5 in Appendix Section 4.1 and A8 in Appendix Section 4.9 also lends some support to the idea that individuals with weak preferences for one group over another, and thus who may view any real-world donation as a positive outcome, may be 
more willing to state low thresholds for non-preferred groups as compared with subjects in the induced preference treatments.

The higher voting thresholds in the Induced Policy \& Budget Treatment are also accompanied with a fall in agreement rates of 10 percentage points compared to the Policy \& Budget Treatment (77.5 compared to 87.2, see the last column of Table 4). In Table 4 we display the agreement rates in each possible committee ideological composition. We find that in both treatments, agreement rates decrease as heterogeneity in peak preferences increases, but the drop appears to be sharper with induced ideologies. Thus, our experimental results show that real ideological choices may grease the wheels of the bargaining process, which runs contrary to the intuition that negotiations under such environments may be tougher due to the nature of the topics in question. This behavior is, however, supported by previous evidence of strong in-group bias fostered by partisan affiliation, which compares in strength to other socially relevant personal characteristics such as race (see Mason (2013); Iyengar and Westwood (2015)).

\begin{tabular}{ccccc}
\hline \multicolumn{4}{c}{ Table 4: } & Induced vs. Elicited Agreement Rates with \\
Policy \& Budget Bargaining, by Committee Composition
\end{tabular}

As noted in the literature review, Christiansen, Georganas and Kagel (2014) is the only experimental investigation of Jackson and Moselle (2002). Directly comparing Christiansen, Georganas and Kagel (2014) to our experiment is not possible because we cannot control the preference distribution which essentially determines the equilibrium outcomes. In particular, all members have different peaks in their experiment, while we focus on committees where two members share an ideological peak preference. Our Induced Policy \& Budget Treatment with induced preferences was designed to indirectly compare our results to those of Christiansen, Georganas and Kagel (2014). Not surprisingly, we then find differences in our results with theirs. Christiansen et al characterize above $90 \%$ of proposals as 2-way splits of the budget which is in contrast to our results in which 3-way 
splits are modal. Furthermore, the authors report an increase in immediate agreement rates when a budgetary division is possible in addition to the policy location choice. We do not find this to be the case, but do find that information on partners' donation choices to real political interest groups increases agreement rates, even when policy is not at stake.

\section{Discussion}

Our experiment is a first attempt at incorporating elements of realism to the study of budgetary and policy negotiations where field studies are non-existent. While we do not claim that our experiment perfectly resembles a natural setting, we believe it brings us closer to the real-world phenomena that we are studying.

Several of our results show support for the game theoretic predictions in our policy and budget bargaining games. Notably, majority members and players whose preferred policy matches the status quo typically propose their preferred policy. More substantively, we find that subjects are willing to make budgetary concessions to implement preferred ideological choices and that our individual preference elicitation method largely correlates with strategic bargaining behavior. We also present suggestive evidence in Appendix Section 4.9 that our behavioral method, while correlated with stated partisan identification and political ideology, may, as has been found in related work, more clearly distinguish "strong" partisans and politically active individuals from weaker partisans and more politically disengaged respondents where non-behavioral elicitation methods might not (Haas and Morton, 2018). These results thus offer some support for the idea that our preference elicitation is doing what we hoped by distinguishing between people who truly hold strong preferences versus those who only say they do.

It has been argued that the possibility to concurrently negotiate over several issues may be conducive to reaching legislative compromises, namely that budgetary transfers may grease the wheels of the bargaining process. Our experimental investigation shows that agreement rates are virtually identical across treatments in which real ideological preferences are displayed regardless of whether subjects negotiate only a budget division, only a policy choice, or both. However, the impossibility to negotiate in a two-dimensional 
space negatively affects political minorities far more than political majorities as evidenced by minority players' lower budgetary transfers, lower chances of proposal approval, and lower possibilities of enacting their preferred policies. Moreover, minority members tend to propose the majority's policy more often than prescribed by the game-theoretic predictions in order to enhance their approval odds.

In light of these findings, one can speculate that majorities may seek an advantage by separating the bargaining process for each dimension so that minorities lose the ability to compromise. In our setting, the bargaining agenda is endogenously fixed, but in the applications that we are attempting to understand, players may actively seek to modify the order of negotiations and bargaining protocol so as to skew outcomes in their favor (see Chen and Eraslan 2013 for theoretical work in this direction).

There are two unanticipated results in our study that underscore the efficacy of information on ideological preferences in reducing bargaining impasses. The first is that when subjects negotiate on two dimensions and preferences over policy are induced by the experimenter, willingness to compromise declines. In the text we have argued that this behavior is consistent with prospect theory since we have framed policy choices in the induced treatment as losses for deviating from one's peak (see Christiansen and Kagel 2019 for related experimental work). Thus, subjects might be more willing to take the risk of disagreement by elevating voting thresholds. However, other motives can play a role, for example, subjects may anticipate that real ideological issues might foster lower willingness to share the budget and thus adjust their thresholds downwards. It can also be that subjects are less willing to take the risk of disagreement in the real ideology setting because they face the possibility of having no monetary reward (only the non-material payoff of group donation), or that subjects view real-life donations as being of value even when they do not go to one's most-preferred interest group.

The second unanticipated result is that agreement rates are lower in the budget division treatment absent information on political preferences. Both unexpected findings suggest that information on policy preferences may help solve the coordination problem of deciding whom to partner with even if policy decisions are not at stake (see Choate, Weymark and 
Wiseman 2019 for a model of legislative bargaining with partisan preferences).

In our theory and experimental design we have abstracted away from several aspects which are quite relevant outside the laboratory. For example, communication has been shown to increase proposer power and lead to more unequal sharing of the budget in the Baron and Ferejohn (1989) game. Will communication also increase the proposer power when policy is at stake? Will minorities benefit from such a possibility? We also do not allow subjects an opportunity to revise their stated preferences. Since members of the ideological majority are better off, it may be that subjects would find it beneficial to misrepresent their true preferences in the bargaining game in order to reap a larger share of the budget. Finally, we do not allow voters to condition their responses on the identity of the proposer. It may well be that members with strong ideological preferences have higher voting thresholds when the offers are made by non-partisans. We leave these and other relevant extensions for future work.

\section{References}

[1] Akerlof, George A and Rachel E Kranton. 2000. "Economics and Identity." The Quarterly Journal of Economics 115(3):715-753."

[2] Baranski, Andrzej and John H. Kagel. 2015. "Communication in Legislative Bargaining." Journal of the Economic Science Association 1(1):59-71.

[3] Baranski, Andrzej and Rebecca Morton. 2020. "The Determinants of Multilateral Bargaining: A Comprehensive Analysis of Baron and Ferejohn Majoritarian Bargaining Experiments." Division of Social Science Working Paper Series WP 37.

[4] Baron, David P and John A Ferejohn. 1989. "Bargaining in Legislatures." American Political Science Review 83(4):1181-1206.

[5] Black, Duncan. 1958. The theory of committees and elections, Cambridge: Cambridge University Press. 
[6] Bodner, Ronit and Drazen Prelec. 2003. "Self-signaling in a Neo-Calvinist Model of Everyday Decision Making." Psychology of Economic Decisions 1:105-126.

[7] Campbell, Angus, Philip E Converse, Warren E Miller and Donald E Stokes. 1980. The American Voter. University of Chicago Press.

[8] Casal, Sandro, Francesco Fallucchi and Simone Quercia. 2019. "The Role of Morals in Three-player Ultimatum Games." Journal of Economic Psychology 70:67-79.

[9] Chandar, Bharat and E Glen Weyl. 2017. "Quadratic Voting in Finite Populations." Available at SSRN 2571026.

[10] Chen, Ying and Hülya Eraslan. 2013. "Informational Loss in Bundled Bargaining." Journal of Theoretical Politics 25(3):338-362.

[11] Choate, Thomas, John A Weymark and Alan E Wiseman. 2019. "Partisan Strength and Legislative Bargaining." Journal of Theoretical Politics 31(1):6-45.

[12] Christiansen, Nels and John H. Kagel. 2019. "Reference Point Effects in Legislative Bargaining: Experimental Evidence." Experimental Economics 22(3):735-752.

[13] Christiansen, Nels, Sotiris Georganas and John H. Kagel. 2014. "Coalition Formation in a Legislative Voting Game." American Economic Journal: Microeconomics $6(1): 182-204$.

[14] Delton, Andrew W, Peter DeScioli and Timothy J. Ryan. 2018. "Moral Obstinacy in Political Negotiations." Working Paper.

[15] Diermeier, Daniel. 2014. "Formal Models of Legislatures." In The Oxford Handbook of Legislative Studies, ed. Shane Martin, Thomas Saalfeld and Kaare W. Strom. Oxford University Press.

[16] Diermeier, Daniel and Rebecca Morton. 2005. "Experiments in Majoritarian Bargaining." In Social Choice and Strategic Decisions, ed. David Austen-Smith and John Duggan. Springer, pp. 201-226. 
[17] Evans, Diana. 2004. Greasing the wheels: Using pork barrel projects to build majority coalitions in Congress. Cambridge University Press.

[18] Farc, Maria-Magdalena and Brad J Sagarin. 2009. "Using Attitude Strength to Predict Registration and Voting Behavior in the 2004 US Presidential Elections." Basic and Applied Social Psychology 31(2):160-173.

[19] Fréchette, Guillaume, John H. Kagel and Massimo Morelli. 2005. "Behavioral Identification in Coalitional Bargaining: An Experimental Analysis of Demand Bargaining and Alternating Offers." Econometrica 73(6):1893-1937."

[20] Greiner, Ben. 2015. "Subject Pool Recruitment Procedures: Organizing Experiments with ORSEE." Journal of the Economic Science Association 1(1):114-125.

[21] Güth, Werner and Eric Van Damme. 1998. "Information, Strategic Behavior, and Fairness in Ultimatum Bargaining: An Experimental Study." Journal of Mathematical Psychology 42(2-3):227-247.

[22] Haas, Nicholas and Rebecca B. Morton. 2018. "Saying Versus Doing: A New Donation Method for Measuring Ideal Points." Public Choice 176(1-2):79-106.

[23] Hill, Seth J and Chris Tausanovitch. 2015. "A Disconnect in Representation? Comparison of Trends in Congressional and Public Polarization." The Journal of Politics $77(4): 1058-1075$.

[24] Holbrook, Allyson L., David Sterrett, Timothy P. Johnson and Maria Krysan. 2016. "Racial Disparities in Political Participation across Issues: The Role of Issue-specific Motivators." Political Behavior 38(1):1-32.

[25] Iyengar, Shanto and Sean J Westwood. 2015. "Fear and loathing across party lines: New evidence on group polarization." American Journal of Political Science $59(3): 690-707$.

[26] Jackson, Matthew O. and Boaz Moselle. 2002. "Coalition and Party Formation in a Legislative Voting Game." Journal of Economic Theory 103(1):49-87. 
[27] Knez, Marc J and Colin F. Camerer. 1995. "Outside Options and Social Comparison in Three-player Ultimatum Game Experiments." Games and Economic Behavior 10(1):65-94.

[28] Krosnick, Jon A. 1988. "Attitude Importance and Attitude Change." Journal of Experimental Social Psychology 24(3):240-255.

[29] Krosnick, Jon A, Stanley Presser, Kaye Husbands Fealing, Steven Ruggles and David L. Vannette. 2015. "The Future of Survey Research: Challenges and Opportunities." The National Science Foundation Advisory Committee for the Social, Behavioral and Economic Sciences Subcommittee on Advancing SBE Survey Research pp. 1-15.

[30] Lalley, Steven P. and E. Glen Weyl. 2018. "Quadratic Voting: How Mechanism Design Can Radicalize Democracy." AEA Papers and Proceedings 108:33-37.

[31] Laroze, Denise, David Hugh-Jones and Arndt Leininger. 2020. The impact of group identity on coalition formation. Technical report School of Economics, University of East Anglia, Norwich, UK.

[32] Lazarus, Jeffrey. 2018. "Bringing back earmarks could grease the wheels for getting bills passed." The Hill. URL: https://thehill.com/blogs/congress-blog/economybudget/383776-bringing-back-earmarks-could-grease-the-wheels-for-getting

[33] Mason, Lilliana. 2013. "The rise of uncivil agreement: Issue versus behavioral polarization in the American electorate." American Behavioral Scientist 57(1):140-159.

[34] Miller, J.M, J.A. Krosnick, A. Holbrook, A. Tahk and L. Dionne. 2016. The Impact of Policy Change Threat on Financial Contributions to Interest Groups. In Explorations in Political Psychology, ed. Jon A Krosnick, I-Chant A Chiang and Tobias H. Stark. Psychology Press pp. 186-216.

[35] Norris, Catherine J, Jon A Krosnick and Penny S. Visser. 2016. Attitude Importance and Attitude-Relevant Knowledge: Motivator and Enabler. In Explorations in 
Political Psychology, ed. Jon A Krosnick, I-Chant A Chiang and Tobias H. Stark. Psychology Press, pp. 217-259.

[36] Okada, Akira and Arno Riedl. 2005. "Inefficiency and social exclusion in a coalition formation game: experimental evidence." Games and Economic Behavior 50(2):278311.

[37] Palfrey, Thomas R. 2016. "Experiments in Political Economy." In Handbook of Experimental Economics, ed. John H. Kagel and Alvin E. Roth. Vol. 2 Princeton University Press, Princeton, NJ.

[38] Posner, Eric A and E. Glen Weyl. 2015. "Voting Squared: Quadratic Voting in Democratic Politics." Vanderbilt Law Review 68:441.

[39] Quarfoot, David, Douglas von Kohorn, Kevin Slavin, Rory Sutherland, David Goldstein and Ellen Konar. 2017. "Quadratic Voting in the Wild: Real People, Real Votes." Public Choice 172(1-2):283-303.

[40] Roth, Alvin E. 1995. "Bargaining Experiments." Handbook of Experimental Economics pp. 253-348.

[41] Tversky, Amos and Daniel Kahneman. 1992. "Advances in Prospect Theory: Cumulative Representation of Uncertainty." Journal of Risk and Uncertainty 5(4):297-323.

[42] Visser, Penny S., Jon A Krosnick and Joseph P. Simmons. 2003. "Distinguishing the Cognitive and Behavioral Consequences of Attitude Importance and Certainty: A New Approach to Testing the Common-factor Hypothesis." Journal of Experimental Social Psychology 39(2):118-141.

[43] Weyl, E. Glen. 2017. "The Robustness of Quadratic Voting." Public Choice 172(12):75-107. 


\title{
Supplemental Online Appendix to Majoritarian Bargaining over Budgetary Divisions and Policy
}

\author{
Andrzej Baranski* $\quad$ Nicholas Haas ${ }^{\dagger} \quad$ Rebecca Morton ${ }^{\ddagger}$
}

July 31,2020

\section{Contents}

1 Subgame Perfect Nash Equilibria Characterization of the Budget and Policy Bargaining Game $\quad 2$

2 Material for Experiments $\quad 4$

2.1 Instructions for Policy \& Budget Treatment . . . . . . . . . . . . . . 4

2.2 Instructions for Budget Only Treatment . . . . . . . . . . . . . . . . . . 10

2.3 Instructions for Policy Only Treatment . . . . . . . . . . . . . . . . 11

2.4 Instructions for Induced Policy \& Budget Treatment . . . . . . . . . . . . 13

2.5 Interest Groups by Topic and Location . . . . . . . . . . . . . . . . . . 16

3 Distribution of Preferences $\quad 17$

4 Complementary Analysis of Hypotheses $\quad 19$

4.1 Hypothesis 1: Voting Thresholds . . . . . . . . . . . . . . . 20

4.1.1 Disaggregation by MAA . . . . . . . . . . . . 20

4.2 Hypothesis 2: Majority Advantage . . . . . . . . . . . . . . 22

4.3 Hypothesis 3: Status Quo Proposer Advantage . . . . . . . . . . . . 24

4.4 Hypothesis 5: Trade-offs and Policy Compromise . . . . . . . . . . . . . . 25

4.5 Hypothesis 6: Voting Thresholds Between Treatments . . . . . . . . . . 26

4.6 Hypothesis 7: One-way Splits, Minimum Winning Coalitions . . . . . . . . 26

4.7 Hypothesis 8: Agreement Rates . . . . . . . . . . . . . . . . . 28

4.8 Hypothesis 9: Elicited Preferences and Voting Behavior . . . . . . . . . . 29

4.9 Hypothesis 10: Induced v. Elicited Preferences . . . . . . . . . . . . . . 31

*Assistant Professor of Economics, New York University Abu Dhabi. Email: a.baranski@nyu.edu

$\dagger$ Assistant Professor of Political Science, Aarhus University. Email: nick.haas@ps.au.dk

${ }^{\ddagger}$ Global Network Professor of Politics, New York University NYC and Abu Dhabi. Email: rebecca.morton@nyu.edu 


\section{Subgame Perfect Nash Equilibria Characterization of the Budget and Policy Bargaining Game}

We will focus on the case when only two players share a peak preference and will distinguish behavior between majority and minority players. It turns out that the policy default location relative to the minority and majority players' peak preferences matters in the characterization of equilibrium so we present the main proposition by cases. Table A1 shows all the possible cases (omitting the reverse ordering of each case because the analysis would be identical). Without loss of generality we refer to players 1 and 2 as the majority players.

Each player's objective is to maximize utility subject to the majority vote constraint. It follows that at most one member will receive a monetary transfer $t$. Normalizing the total budget to 1 , we can write the problem for player $i$ as follows:

$$
\begin{array}{cc}
\max Y \in\{L, M, R\}, t \geq 0 & 1-t-M A A_{i}^{\hat{Y}_{i} \rightarrow Y} \\
\text { subject to } & \exists j \neq i \text { such that } t-M A A_{j}^{\hat{Y}_{j} \rightarrow Y} \geq-M A A_{i}^{\hat{Y}_{j} \rightarrow Y} .
\end{array}
$$

Since utility is decreasing in transfers it must be that, when equilibrium entails a monetary transfer, the optimal transfer $t^{*}$ is given by

$$
t^{*}=\max \left\{0, M A A_{j}^{\hat{Y}_{j} \rightarrow Y}-M A A_{j}^{\hat{Y}_{j} \rightarrow Y^{\mathrm{o}}}\right\}
$$

Thus, a player proposes a positive transfer only when the proposed policy $Y$ is such that both other players are made worse off vis-a-vis the default outcome. Clearly, the proposer will transfer to the player who suffers the least from the policy choice. When

only one player is made worse off and the other's utility is at least as large as with the default policy, then no transfers take place.

It is straightforward to see that a pair $\left(t^{*}, Y^{*}\right)$ that maximizes Problem (1) exists because there are a finite number of policies and for each policy there exists an associated 
optimal transfer. It should also be noted that disagreement is not part of any equilibrium because all players vote in favor of the default.

Now consider the committee composition in which two players ( 1 and 2 without loss of generality) share a peak preference and player 3 denotes the minority player. Table A1 presents the possible combinations of preferences and default policies that may arise. We say that a player compromises on policy whenever she proposes another player's preferred policy (i.e. $Y \neq \hat{Y}_{i}$ ), and a player compromises on the budget whenever she transfers a positive amount and proposes her preferred policy.

Table A1: Possible Committee Preference Distributions and Default Policies in a

\begin{tabular}{llll}
\multicolumn{4}{c}{ Majority Minority Situation } \\
Case & Left & Middle & Right \\
1 & $\mathrm{P} 1, \mathrm{P} 2, Y^{0}$ & $\mathrm{P} 3$ & \\
2 & $\mathrm{P} 1, \mathrm{P} 2$ & $\mathrm{P} 3, Y^{0}$ & \\
3 & $\mathrm{P} 1, \mathrm{P} 2$ & $\mathrm{P} 3$ & $Y^{0}$ \\
4 & $\mathrm{P} 1, \mathrm{P} 2, Y^{0}$ & & $\mathrm{P} 3$ \\
5 & $\mathrm{P} 1, \mathrm{P} 2$ & $Y^{0}$ & $\mathrm{P} 3$ \\
6 & $\mathrm{P} 1, \mathrm{P} 2$ & & $\mathrm{P} 3, Y^{0}$ \\
7 & $Y^{0}$ & $\mathrm{P} 1, \mathrm{P} 2$ & $\mathrm{P} 3$ \\
8 & & $\mathrm{P} 1, \mathrm{P} 2, Y^{0}$ & $\mathrm{P} 3$ \\
9 & & $\mathrm{P} 1, \mathrm{P} 2$ & $\mathrm{P} 3, Y^{0}$
\end{tabular}

Notes: Only cases where Players 1 and 2 are to the left of Player 3 are listed. The analysis of other cases follows the same logic.

The following results follow from the characterization of the optimal transfer.

Lemma 1. Consider the cases described in Table A1. The following holds in equilibrium

1. Default policy advantage: If $\hat{Y}_{i}=Y^{\mathrm{o}}$ then player $i$ does not compromise on any dimension. 
2. Majority players do not compromise: (Cases 1-9) For any committee preference distribution and default policy location, majority players do not compromise on any dimension (i.e. $t^{*}=0$ and $Y=Y_{M A J}$ ).

\section{Minority players may or may not compromise:}

(a) Minority players do not compromise on policy or budget: (Cases 2,3,6,9) Whenever the default is closer to the minority player's peak (or equal to) than to the majority players' peaks, the minority player proposes $t^{*}=0$ and $Y=\hat{Y}_{3}$. Both Majority players vote in favor.

(b) Minority may compromise on policy or budget: (Case 1,4,7,8) Whenever the default is closer to the majority players' peaks (or equal to) than to the minority player's peak, the minority player may find it optimal to compromise on a budgetary division with the majority player who has the lowest disutility from moving away from the default. If the transfer is too large, the minority player may compromise on policy by choosing $Y=\hat{Y}_{1}$ and $t^{*}=0$.

(c) Minority players may seek middle ground: (Cases 4 and 5) In case 5 the minority player will not transfer any money and leaves the policy in the middle if this yields higher utility than choosing her favorite policy and compensating the majority partners with the lowest disutility from moving away from the default. In case 4, a middle ground agreement can be reached but this would entail a positive transfer to the cheapest majority player.

\section{Material for Experiments}

\subsection{Instructions for Policy \& Budget Treatment}

Welcome to the Economics Laboratory. In this experiment, you will participate in 5 parts that we fully explain below. You will be paid for your participation in cash at the end of the session. First, we will describe parts 1, 2, and 3. After you have completed these parts, we will distribute the instructions for parts 4 and 5 . 


\section{Part 1.}

In this part you will answer a short survey with questions about yourself.

\section{Part 2.}

In this part, you will be shown four different groupings of three interest groups each. Groupings are organized around topic area, and each grouping will include interest groups that are actively involved on the same topic. For example, one interest grouping might contain interest groups whose area of focus is the issue of abortion, a second grouping might contain interest groups whose area of focus is the issue of health insurance, and so on.

Within each grouping, the three different interest groups will have different stances on the topic at hand: so, for instance, if the topic was abortion, there might be one interest group that was firmly against abortion in all contexts, a second that was against abortion in all contexts except when the mother's life was in danger, and a third that was firmly in favor of abortion being legal in all contexts. Again, this is just an example; abortion is not one of the topic areas and you will not see interest groups with different stances on the issue of abortion.

Your task in Part 2 will be to decide for each of the four topics to which interest group you want us (the experimenters) to donate $\$ 1$ on your behalf. After you have made decisions for all four topics, the computer will randomly choose one of your four decisions to be the one that "counts", that is, which of the four decisions we will implement and to which interest group we will donate $\$ 1$ on your behalf. After the experiment is over, you will learn which of your four decisions "counted". Within a week of your completion of the study, we will also share with you a link to a website where we will post receipts of donations so that you can verify that donations were made as promised.

For completing this part of the experiment you will earn $\$ 2$.

\section{Part 3.}

In this part, you will revisit each of the four topics and their associated interest groups that you saw in Part 2. We refer to whichever group you decided to allocate the $\$ 1$ as your "preferred interest group". 
In this Part, there is a chance (we explain how this chance is determined below) that we will donate $\$ 100$ on your behalf to your same preferred interest group for each topic area. However, there is also a chance that we will donate $\$ 100$ not to your preferred interest group but instead to one of the two other interest groups in this topic area. You can play a role in preventing the $\$ 100$ from going to one of the two other interest groups that are not your preferred interest group, and therefore in ensuring that the $\$ 100$ goes to your preferred interest group instead.

Specifically, we will ask you to state the minimum amount between $\$ 0$ and $\$ 5$ that you would need to be paid in order to accept $\$ 100$ going to each of your non-preferred interest groups instead of your preferred group. We will call this amount your Minimum Acceptable Amount (MAA). Once you state your MAA, the computer will randomly draw a number between 0 and 5. If the number drawn is lower than your MAA, the donation of the $\$ 100$ remains to your originally stated favorite group and you are paid nothing from this task. If the randomly drawn number is greater than or equal to your stated number, you will be paid the drawn number in addition to your earnings from your participation in this study, and the $\$ 100$ will be donated on your behalf to a non-preferred interest group. Your MAA can be any number between $\$ 0$ and $\$ 5$, including $\$ 0$ and $\$ 5$, to the second decimal place. The number that the computer draws will also be between $\$ 0$ and $\$ 5$, to the second decimal place, but cannot include $\$ 0$ or $\$ 5$.

This means that if you feel very strongly that the $\$ 100$ should go to your preferred group and not to an alternative interest group, you can block it from going to the alternative interest group, and therefore ensure that it goes to your preferred group, by stating $\$ 5$ as your MAA: this means that you will not accept any amount less than $\$ 5$ (which is greater than the maximum you could possibly receive, $\$ 4.99$ ) for the $\$ 100$ to go to a non-preferred interest group. Alternatively, if you do not feel at all strongly that the $\$ 100$ should not go to a group that is not your preferred interest group, you can choose $\$ 0$ as your MAA: this means that you would accept any amount to have the $\$ 100$ go to a non-preferred interest group. Of course, you may feel somewhere between not at all strongly and very strongly, in which case you can name a MAA between $\$ 0$ and $\$ 5$. 
Here is an example. Imagine that your favorite group is GROUP1. What is your MAA to accept that we will instead donate $\$ 100$ to a non-preferred GROUP2? Suppose you choose $\$ 2$ and the computer draws $\$ 4$. Then, because $\$ 4$ is greater than your MAA $(\$ 2)$, you are paid $\$ 4$ and we donate $\$ 100$ to GROUP 2 and $\$ 0$ to GROUP1. If the randomly drawn number was less than $\$ 2$, then because it would be less than your MAA $(\$ 2)$, you would get $\$ 0$ and the $\$ 100$ would be assigned to your preferred group, GROUP1. For each topic area, we will ask you to state a MAA for both non-preferred groups. So continuing with the above example, we would ask you to state your MAA both for GROUP2 and GROUP3. Once you have made all of your decisions, a computer will randomly determine whether one of your decisions "counts" and therefore whether $\$ 100$ will be donated on your behalf to either a non-preferred or preferred interest group. The computer will choose one participant from each experiment session at random and one of his or her choices will be implemented and will count for payment. For completing this part of the experiment you will be paid $\$ 2$ plus any additional potential earnings as determined by your decisions and chance, and as explained above.

After the experiment is over, you will learn whether one of your decisions "counted", and if so, which one. Once we have completed our study, we will also share with you a link to a website where we will post receipts of donations so that you can verify that donations were made as promised.

\section{Part 4.}

You will participate in 8 rounds of the task described below. You will learn the outcomes of the rounds at the end of the experiment.

At the start of each round, you will be randomly assigned to a committee of three people. Everyone in each committee will be present in the laboratory and will be making decisions in real time. Your committee will be endowed with $\$ 10$. As a group, your task is to decide on two things by majority $(2 / 3)$ vote. First, you must decide how to split the $\$ 10$ between the three of you.

Second, you will be shown three interest groups with different stances on the issue of either welfare, taxes, immigration, or guns. You will play two rounds with each topic area: 
so you will play two rounds with interest groups whose area of focus is welfare, two rounds with interest groups whose area of focus is taxes, and so on. You will be shown a short summary of each interest group's stance on the issue that will be taken directly from the group's official materials. Note that the groups and the summaries will be the same as they were in Parts 2 and 3 of this experiment. Your second task will be to decide to which of the three interest groups you want us (the experimenters) to donate an additional $\$ 100$ on the committee's behalf. Once all committees have made all of their decisions and the experiment session is over, a computer will randomly select one committee to count and we will divide the $\$ 10$ and donate $\$ 100$ to the interest group that the committee selected in that decision.

After the experiment is over, you will learn whether one of your committee's decisions counted, and if so, which one. Within a week of your completion of the study, we will also share with you a link to a website where we will post receipts of donations so that you can verify that donations were made as promised.

The voting will work in the following way. First, each of the three committee members will make a proposal for how the $\$ 10$ should be divided and to which interest group the $\$ 100$ should go. Prior to submitting a proposal, you will have two pieces of information about the other players in your committee that you can use or not use as you wish. Both pieces of information will come from the players' decisions in Parts 2 and 3 of the experiment. The first piece of information you will have is which interest group of the three they prefer; this was determined by their choice of which to donate $\$ 1$ to. The second piece of information you will have is their stated Minimum Acceptable Amount (MAA) between $\$ 0$ and $\$ 5$ to accept $\$ 100$ being donated on their behalf to a non-preferred interest group. The first piece of information should tell you a player's interest group preference, and the second piece should tell you how strongly they favor their preferred interest group relative to non-preferred interest groups.

After making your proposal but prior to knowing which proposal was chosen, you will also be asked to state the Minimum Offer (MO) of the $\$ 10$ that you would have to be offered to accept a proposal where $\$ 100$ is donated on your committee's behalf to each of 
the three interest groups. If the amount offered to you is equal to or greater than what you specified, then your vote will be counted in favor of the proposal. If the amount offered to you is less, then your vote will be counted against the proposal. Your MO can be any number between $\$ 0$ and $\$ 10$, including $\$ 0$ and $\$ 10$, to the second decimal place.

This means that if you feel very strongly that the $\$ 100$ should NOT go to the group, you can state $\$ 10$ as your Minimum Offer (MO): this means that you will not accept any amount less than $\$ 10$ (which is the maximum you could possibly receive) for the $\$ 100$ to go to the group. Alternatively, if you feel very strongly that the $\$ 100$ SHOULD go to the group, you can choose $\$ 0$ as your MO: this means that you would accept any amount to have the $\$ 100$ go to this group. Of course, you may feel somewhere between these options, in which case you can name a MO between $\$ 0$ and $\$ 10$.

Once the members in your committee have submitted their proposals and stated their MOs, the computer will randomly choose one of your proposals to be the one that the group votes on. The voting is by majority and will work in the following way:

1. If a majority ( 2 or more) of committee members vote in favor of the proposed division and group donation, then the result will be binding. Should your committee decision be randomly chosen to be the one from the experiment session that counts, then each of you will receive the amount of money specified in the division of the $\$ 10$ and $\$ 100$ will be assigned to the interest group on behalf of the committee's members.

2. If the majority ( 2 or more) of committee members vote against the proposal then the $\$ 10$ vanishes (no one in the committee gets any amount) and the $\$ 100$, should your committee's decision be randomly selected to be the one from the experiment session that counts, will be donated to a randomly selected interest group on the committee's behalf. You will know to which randomly selected group the money would go prior to stating your MOs.

For completing this part of the experiment you will earn between $\$ 0$ and $\$ 10$, depending on your choices, the choices of others in your committee, and chance, as specified above. 


\section{Part 5.}

You will be asked a few follow up questions.

\subsection{Instructions for Budget Only Treatment}

Parts $1,2,3$ and 5 remain the same.

\section{Part 4.}

You will participate in 8 rounds of the task described below. You will learn the outcomes of the rounds at the end of the experiment.

At the start of each round, you will be randomly assigned to a committee of three people. Everyone in each committee will be present in the laboratory and will be making decisions in real time. Your committee will be endowed with $\$ 10$. As a committee, your task is to decide by a majority $(2 / 3)$ vote how to split the $\$ 10$ between the three of you.

Once all committees have made all of their decisions and the experiment session is over, a computer will randomly select one committee to count and we will divide the $\$ 10$ between committee members in accordance with what the committee decided. After the experiment is over, you will learn whether one of your committee's decisions counted, and if so, which one.

The voting will work in the following way. First, each of the three committee members will make a proposal for how the $\$ 10$ should be divided. Prior to submitting a proposal, you will have two pieces of information about the other players in your committee that you can use or not use as you wish. Both pieces of information will come from the players' decisions in Parts 2 and 3 of the experiment. The first piece of information you will have is which interest group of the three they prefer; this was determined by their choice of which to donate $\$ 1$ to. The second piece of information you will have is their stated Minimum Acceptable Amount (MAA) between $\$ 0$ and $\$ 5$ to accept $\$ 100$ being donated on their behalf to a non-preferred interest group. The first piece of information should tell you a player's interest group preference, and the second piece should tell you how strongly they favor their preferred interest group relative to non-preferred interest groups.

After making your proposal but prior to knowing which proposal was chosen, you will 
also be asked to state the Minimum Offer (MO) of the $\$ 10$ that you would have to be offered for you to accept the proposal. If the amount offered to you is equal to or greater than what you specified, then your vote will be counted in favor of the proposal. If the amount offered to you is less, then your vote will be counted against the proposal. Your MO can be any number between $\$ 0$ and $\$ 10$, including $\$ 0$ and $\$ 10$, to the second decimal place.

Once the members in your committee have submitted their proposals and stated their MOs, the computer will randomly choose one of your proposals to be the one that the group votes on. The voting is by majority and will work in the following way:

1. If a majority ( 2 or more) of committee members vote in favor of the proposed division, then the result will be binding. Should your committee decision be randomly

chosen to be the one from the experiment session that counts, then each of you will receive the amount of money specified in the division of the $\$ 10$.

2. If the majority ( 2 or more) of committee members vote against the proposal then the $\$ 10$ vanishes (no one in the committee gets any amount).

For completing this part of the experiment you will earn between $\$ 0$ and $\$ 10$, depending on your choices, the choices of others in your committee, and chance, as specified above.

\subsection{Instructions for Policy Only Treatment}

Parts 1,2,3 and 5 remain the same.

\section{Part 4.}

You will participate in 8 rounds of the task described below. You will learn the outcomes of the rounds at the end of the experiment.

At the start of each round, you will be randomly assigned to a committee of three people. Everyone in each committee will be present in the laboratory and will be making decisions in real time. 
You will be shown three interest groups with different stances on the issue of either welfare, taxes, immigration, or guns. You will play two rounds with each topic area: so you will play two rounds with interest groups whose area of focus is welfare, two rounds with interest groups whose area of focus is taxes, and so on. You will be shown a short summary of each interest group's stance on the issue that will be taken directly from the group's official materials. Note that the groups and the summaries will be the same as they were in Parts 2 and 3 of this experiment. Your task will be to decide to which of the three interest groups you want us (the experimenters) to donate an additional $\$ 100$ on the committee's behalf. Once all committees have made all of their decisions and the experiment session is over, a computer will randomly select ONE committee to count and we will donate $\$ 100$ to the interest group that the committee selected in that decision.

After the experiment is over, you will learn whether one of your committee's decisions counted, and if so, which one. Within a week of your completion of the study, we will also share with you a link to a website where we will post receipts of donations so that you can verify that donations were made as promised.

The voting will work in the following way. First, each of the three committee members will make a propose to which interest group the $\$ 100$ should go. Prior to submitting a proposal, you will have two pieces of information about the other players in your committee that you can use or not use as you wish. Both pieces of information will come from the players' decisions in Parts 2 and 3 of the experiment. The first piece of information you will have is which interest group of the three they prefer; this was determined by their choice of which to donate $\$ 1$ to. The second piece of information you will have is their stated Minimum Acceptable Amount (MAA) between $\$ 0$ and $\$ 5$ to accept $\$ 100$ being donated on their behalf to a non-preferred interest group. The first piece of information should tell you a player's interest group preference, and the second piece should tell you how strongly they favor their preferred interest group relative to non-preferred interest groups.

After making your proposal but prior to knowing which proposal was chosen, you will also be asked to state for which group(s) you would vote in favor of donating the $\$ 100$. 
Once all members have submitted the groups they would vote in favor or, the computer will randomly choose one of your proposals to be the one that the group votes on. The voting is by majority and will work in the following way:

1. If a majority ( 2 or more) of committee members vote in favor of the group donation, then the result will be binding. Should your committee decision be randomly chosen to be the one from the experiment session that counts, then the $\$ 100$ will be assigned to the interest group on behalf of the committee's members.

2. If the majority ( 2 or more) of committee members vote against the proposal then the $\$ 100$, should your committee's decision be randomly selected to be the one from the experiment session that counts, will be donated to a randomly selected interest group on the committee's behalf. You will know to which randomly selected group the money would go prior to stating your which groups you would vote in favor of.

For completing this part of the experiment you will earn $\$ 3.5$.

\subsection{Instructions for Induced Policy \& Budget Treatment}

Welcome to the Economics Laboratory. In this experiment, you will participate in 2 parts that we fully explain below. You will be paid for your participation in cash at the end of the session. Part 1. In this part you will answer a short survey with questions about yourself. For completing this part of the experiment you will earn $\$ 2$. Part 2. You will participate in 8 rounds of the task described below. You will learn the outcomes of the rounds at the end of the experiment. At the start of each round, you will be randomly assigned to a committee of three people. Everyone in each committee will be present in the laboratory and will be making decisions in real time. Your committee will be endowed with $\$ 10$. As a group, your task is to decide on two things by majority $(2 / 3)$ vote. First, you must decide how to split the $\$ 10$ between the three of you. Second, you will play a game in which you will decide where to locate a given facility. Each of you will be assigned a personal location, called "Your Personal Location." The closer the facility is to Your Personal Location, the better off you will be. For example, suppose 
that you are bargaining where to locate a bus stop for which you have three options: left, middle, or right. Each of you in the committee will have a Personal Location. These Personal Locations are assigned randomly to each of you. The facilities for which you will decide a location are a bus stop, an airport, a police station, and a hospital. Since there are 8 bargaining rounds, each facility will be the subject of bargaining in two different rounds. To continue with our example, if the committee agrees to locate the bus stop on the left, and Your Personal Location is another place, you will suffer a loss between $\$ 0$ and $\$ 5$. At the start of the bargaining round you will be told Your Personal Location, your loss for other locations, and everyone else's Personal Locations and losses associated to locations away from them. If your committee agrees to locate the bus stop at Your Personal Location, you do not suffer any loss. Prior to each bargaining round, you will be endowed with $\$ 5$ to insure that you do not lose money on any round. Once all committees have made all of their decisions and the experiment session is over, the computer will randomly select ONE committee to "count" and we will divide the $\$ 10$ and locate the facility according to what the committee selected in that decision. From your $\$ 5$ endowment for that round you will be deducted the loss, if any, corresponding to the location of the facility. After the experiment is over, you will learn whether one of your committee's decisions "counted", and if so, which one.

Voting will work in the following way. First, each of the three committee members will make a proposal for how the $\$ 10$ should be divided and where to locate the facility.

After making your proposal but prior to knowing which proposal was chosen, you will also be asked to state the Minimum Offer (MO) of the $\$ 10$ that you would have to be offered to accept a proposal for each possible location. If the amount offered to you is equal to or greater than what you specified, then your vote will be counted in favor of the proposal. If the amount offered to you is less, your vote will be counted against the proposal. Your MO can be any number between $\$ 0$ and $\$ 10$, including $\$ 0$ and $\$ 10$, to the second decimal place.

This means that if you feel very strongly that the facility should not be placed at a given location, you can state $\$ 10$ as your Minimum Offer (MO): this means that you will 
not accept any amount less than $\$ 10$ (which is the maximum you could possibly receive). Alternatively, if you feel very strongly that the facility should be placed in a given location, you can choose $\$ 0$ as your MO: this means that you would accept any amount to have the facility placed in the given location. Of course, you may feel somewhere between these options, in which case you can name a MO between $\$ 0$ and $\$ 10$.

Once the members in your committee have submitted their proposals and stated their MOs, the computer will randomly choose one of your proposals to be the one that the group votes on. The voting is by majority and will work in the following way:

1. If a majority (2 or more) of committee members vote in favor of the proposed division and facility location, then the result will be binding. Should your committee decision be randomly chosen to be the one from the experiment session that "counts", then each of you will receive the amount of money specified in the division of the $\$ 10$ and the facility will be located accordingly. Any loss in the event that the facility is placed away from Your Personal Location will be deducted from your $\$ 5$ endowment.

2. If the majority ( 2 or more) of committee members vote against the proposal then the $\$ 10$ vanishes (no one in the committee gets any amount) and the facility will be placed at a random location. You will know at which randomly selected location the facility would be placed prior to stating your MOs. Should your decision be the one randomly selected to be the one from the experiment session that counts, then you will be paid $\$ 5$ minus any losses associated with the facility location decision.

For completing this part of the experiment you will earn between $\$ 0$ and $\$ 15$, depending on your choices, the choices of others in your committee, and chance, as specified above. 


\subsection{Interest Groups by Topic and Location}

Figure A1: Interest Groups by Topic and Location

\begin{tabular}{|c|c|c|c|}
\hline \multirow[b]{2}{*}{ Topic } & \multicolumn{3}{|c|}{ Ideological Location of Interest Group } \\
\hline & $\begin{array}{c}\text { Ideologically Democrat } \\
\text { (Left) }\end{array}$ & $\begin{array}{c}\text { Ideologically } \\
\text { Independent (Middle) }\end{array}$ & $\begin{array}{c}\text { Ideologically } \\
\text { Republican (Right) }\end{array}$ \\
\hline Taxes & Citizens for Tax Justice & The Tax Foundation & $\begin{array}{c}\text { Americans for Tax } \\
\text { Reform }\end{array}$ \\
\hline Welfare & $\begin{array}{c}\text { Center for American } \\
\text { Progress }\end{array}$ & $\begin{array}{c}\text { Child Welfare League of } \\
\text { America }\end{array}$ & Heritage Foundation \\
\hline Immigration & $\begin{array}{c}\text { American Immigration } \\
\text { Council }\end{array}$ & $\begin{array}{l}\text { The Migration } \\
\text { Policy Institute }\end{array}$ & $\begin{array}{c}\text { Negative Population } \\
\text { Growth }\end{array}$ \\
\hline Guns & $\begin{array}{c}\text { Coalition to Stop Gun } \\
\text { Violence }\end{array}$ & $\begin{array}{c}\text { The American Security } \\
\text { Project }\end{array}$ & $\begin{array}{l}\text { National Rifle } \\
\text { Association }\end{array}$ \\
\hline
\end{tabular}

Notes: The image subjects were shown on interest groups used in the study, by topic area and placement on the ideological spectrum. 


\section{Distribution of Preferences}

Figure A2: Distribution of Peak Preferences by Topic Area

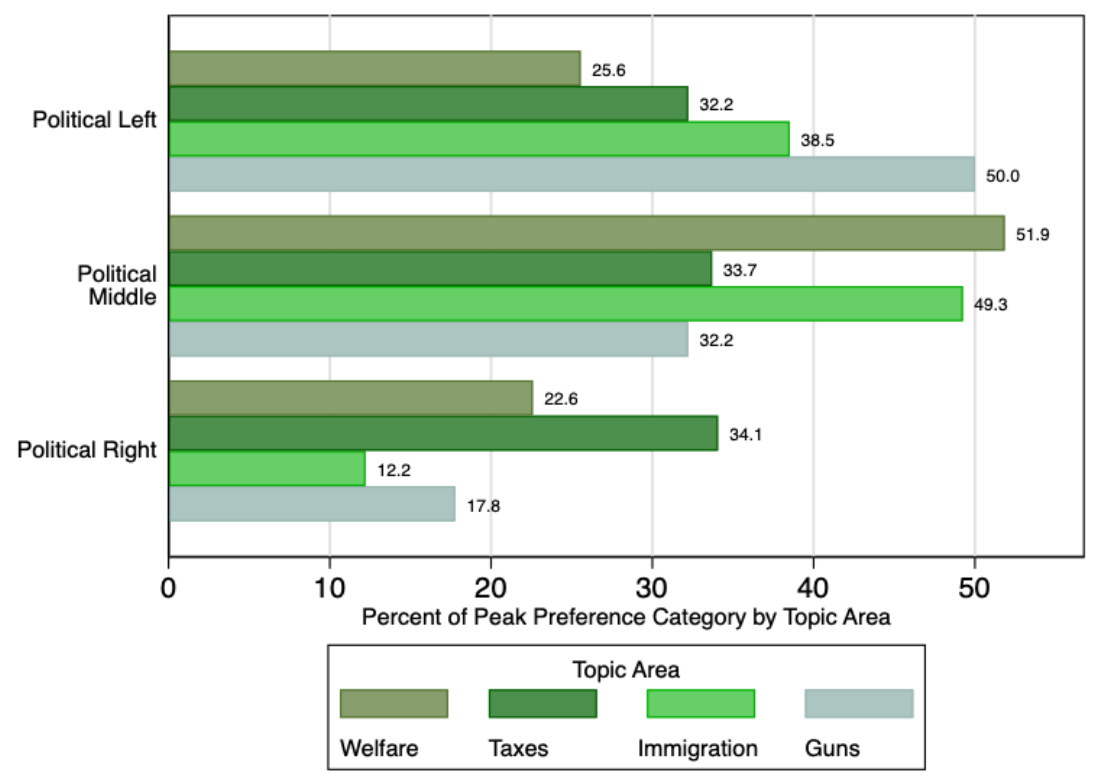

Notes: This figure shows the percentage of subjects within a given topic area (welfare, taxes, immigration, or guns) selecting the left, middle, or right (on the political spectrum) interest group as their most preferred. 
Figure A3: Cumulative Distribution Function of Minimum Acceptable Amounts by Topic Area: Left/Right Peak Preference Players Only
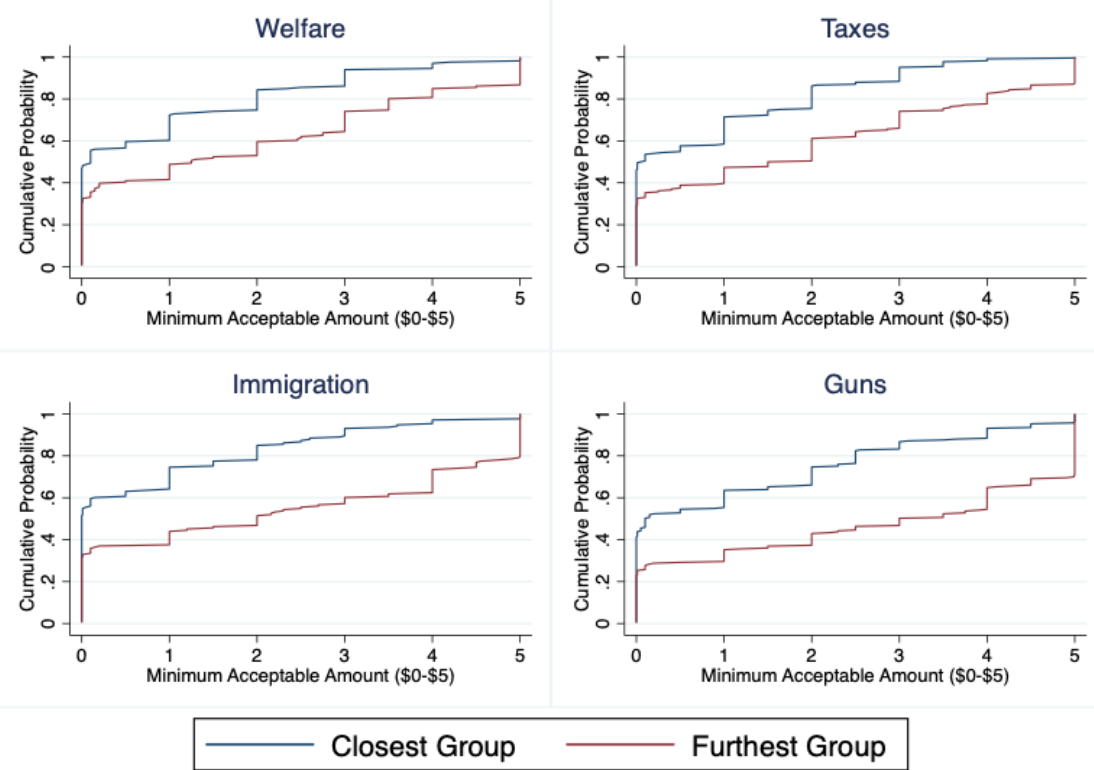

Notes: This figure displays cumulative distribution functions of individuals' stated MAAs for non-preferred interest groups by topic area. We distinguish between groups that are closer (middle political group) versus further (left or right political group) to one's preferred group (either left or right political group). As would be expected, individuals with extreme peak (left or right political group) preferences feel more favorably toward the middle (closest) political group as compared with the (furthest) political group at the opposite extreme. Kolmogorov-Smirnov tests indicate that the distribution functions are not equal for all four topic areas $(\mathrm{p}=0: 00)$. 
Figure A4: Cumulative Distribution Function of Minimum Acceptable Amounts by Topic Area: Middle Peak Preference Players Only
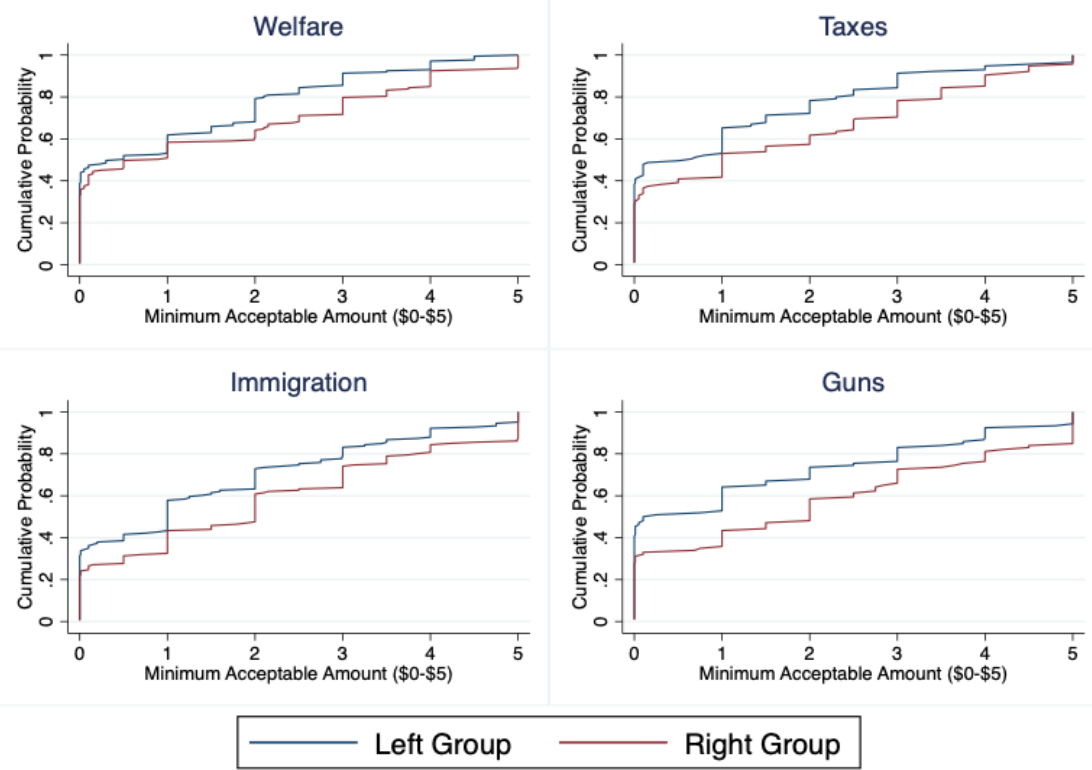

Notes: This figure displays cumulative distribution functions of individuals' stated MAAs for non-preferred interest groups by topic area. Because we look at middle-peak players, we cannot a priori predict whether the left or right political group is closer or further from a subject's preferred group, so we show MAAs split by whether they are for the left or right political group. For all four topic areas, we can see that subjects state lower MAAs for left groups as compared with right groups, indicating that the sample leans left. Kolmogorov-Smirnov tests indicate that the distribution functions are not equal for the guns topic area $(\mathrm{p}=0: 05)$, but we cannot reject the null hypothesis that the distributions are equal for the welfare $(\mathrm{p}=0: 25)$, taxes $(\mathrm{p}$ $=0: 31)$, and immigration $(\mathrm{p}=0: 10)$ topic areas.

\section{Complementary Analysis of Hypotheses}

This Section reports additional analyses, organized by hypothesis, along with regression output for figures appearing in the main text. 


\subsection{Hypothesis 1: Voting Thresholds}

\subsubsection{Disaggregation by MAA}

For simplicity, Figure 1, which displays subjects' voting thresholds for preferred and nonpreferred interest groups, pools across non-preferred interest groups. However, as is clear from Figures A3 and A4, the degree to which subjects viewed different non-preferred interest groups as undesirable varied substantially. Further, a portion of subjects stated $\$ 0$ minimum acceptable amounts for non-preferred interest groups, suggesting that the degree to which they preferred their "preferred" interest group over the "non-preferred" interest group was minimal.

Figure A5 takes into account variation in preference intensity by further disaggregating voting thresholds by non-preferred interest group type. A non-preferred interest group may be closer or further from one's own preferred group than the alternative non-preferred group, or it may be equidistant, as determined by one's stated minimum acceptable amount. Those who feel similarly toward both alternative non-preferred interest groups (the "equidistant" respondents) may state MAAs of $\$ 0$ for both non-preferred groups (indicating that their preference for their "preferred" interest group over non-preferred groups is minimal), or they may state equal MAAs above $\$ 0$ for both non-preferred groups (indicating that they are neutral between non-preferred groups). In Figure A5, we use stated MAAs to evaluate subjects' voting thresholds for non-preferred interest groups that are second-least versus least preferred. In cases where subjects stated the same MAAs for both non-preferred groups, we distinguish between those who stated MAAs of $\$ 0$ for both non-preferred groups (indicating that they felt similarly about all three interest groups, or at least that their preference for their "preferred group" over alternative groups was minimal) and those who stated MAAs above $\$ 0$ for both non-preferred groups (indicating that they felt similarly about both non-preferred groups, but still preferred their "preferred group" over those two alternatives). 
Figure A5: Voting Thresholds by Non-Preferred Interest Group Type
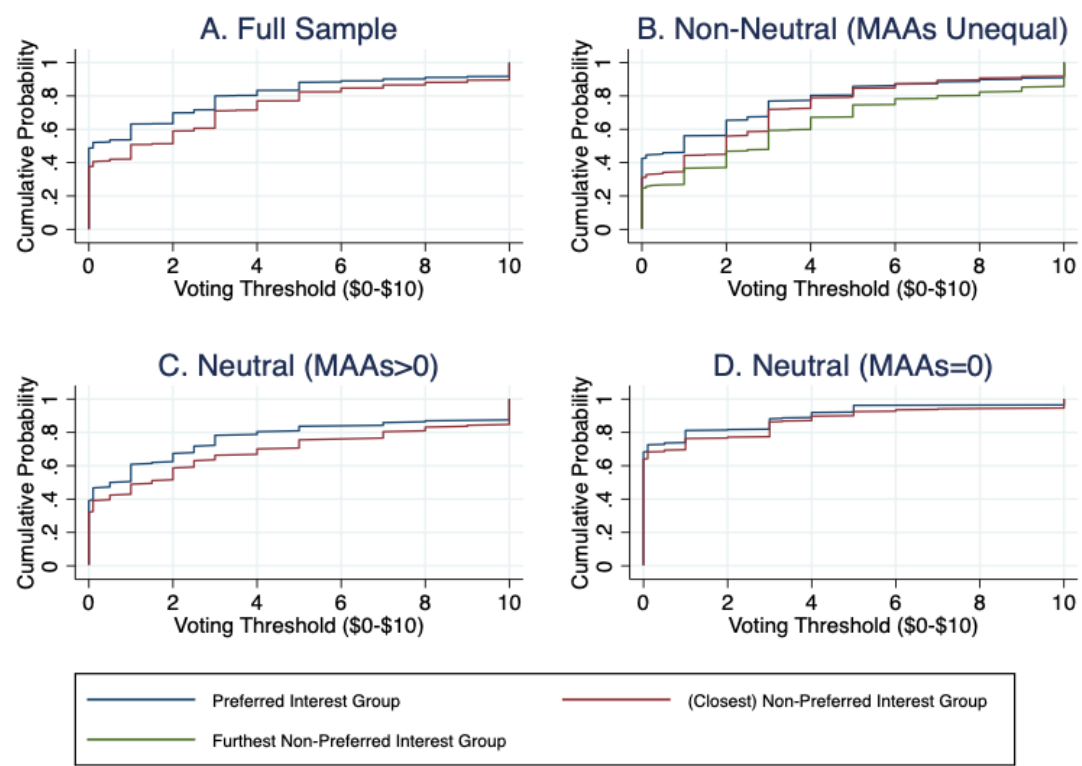

Notes: This figure displays cumulative distribution functions of individuals' voting thresholds for all subjects in the Policy \& Budget Treatment (panel A), only those subjects who stated unequal MAAs for non-preferred groups (panel B), only those subjects who stated equal non-zero MAAs for both nonpreferred groups (panel C), or only those subjects who stated equal MAAs of $\$ 0$ for both non-preferred groups (panel D). Voting thresholds are shown for preferred versus non-preferred interest groups or, in the case where subjects felt differently about the two alternative interest groups (panel B), thresholds for the preferred and the least and second least preferred groups.

Results are similar to Figure 1, and the disaggregation further attests not only to Hypothesis 1 but also to the correspondence between voting thresholds and MAAs. Panel A shows again that for the full sample, subjects tend to state higher voting thresholds for non-preferred interest groups than for preferred interest groups, indicating that they are willing to accept a smaller share of the budget when the policy is their preferred one (Hypothesis 1). Panel B disaggregates non-preferred interest groups by the degree to which they were not preferred (and is thus limited to subjects who stated unequal MAAs 
for the two alternative groups). Consistent with expectation, we see that subjects are more likely to trade off policy and budget for second-least preferred groups than for least preferred groups (as determined by stated MAAs).

What about subjects who stated equal MAAs for both alternative non-preferred interest groups? Consistent with the findings above, Panel $\mathrm{C}$ shows that subjects tend to state higher voting thresholds for non-preferred interest groups than for preferred groups when the sample is limited to those subjects who stated equal MAAs above zero for both alternative interest groups. In contrast, panel D shows that the gap between preferred and non-preferred groups narrows substantially among subjects who stated MAAs of $\$ 0$ for both alternative interest groups. This is what we would expect: when MAAs indicate that subjects feel equally about alternative interest groups but prefer the group they selected as most preferred (panel C), the gap remains between preferred and non-preferred groups when considering voting thresholds. When MAAs of $\$ 0$ indicate that subjects feel similarly about all three interest groups (panel D), voting thresholds show that subjects do not differentiate between "preferred" and "non-preferred" groups.

Interestingly, panel D shows that while subjects who stated MAAs of $\$ 0$ do not differentiate between preferred and non-preferred interest groups when considering voting thresholds, it also indicates they do not have weak preferences. Put differently, a large portion of these subjects are willing to accept $\$ 0$ when considering either preferred or non-preferred groups, suggesting that while subjects feel somewhat neutrally about the three interest groups, they still view all groups as worthy of a donation. As noted in the text, one reason for the differences between induced and naturally occurring treatments may be that, when considering real-world donations, individuals may not be so opposed to those donations going to marginally less preferred groups, as they may feel that such donations still make a positive difference.

\subsection{Hypothesis 2: Majority Advantage}

Figure A6 below reproduces Figure 1 separately for majority and minority players. 
Figure A6: Voting Thresholds by Non-Preferred Interest Group Type

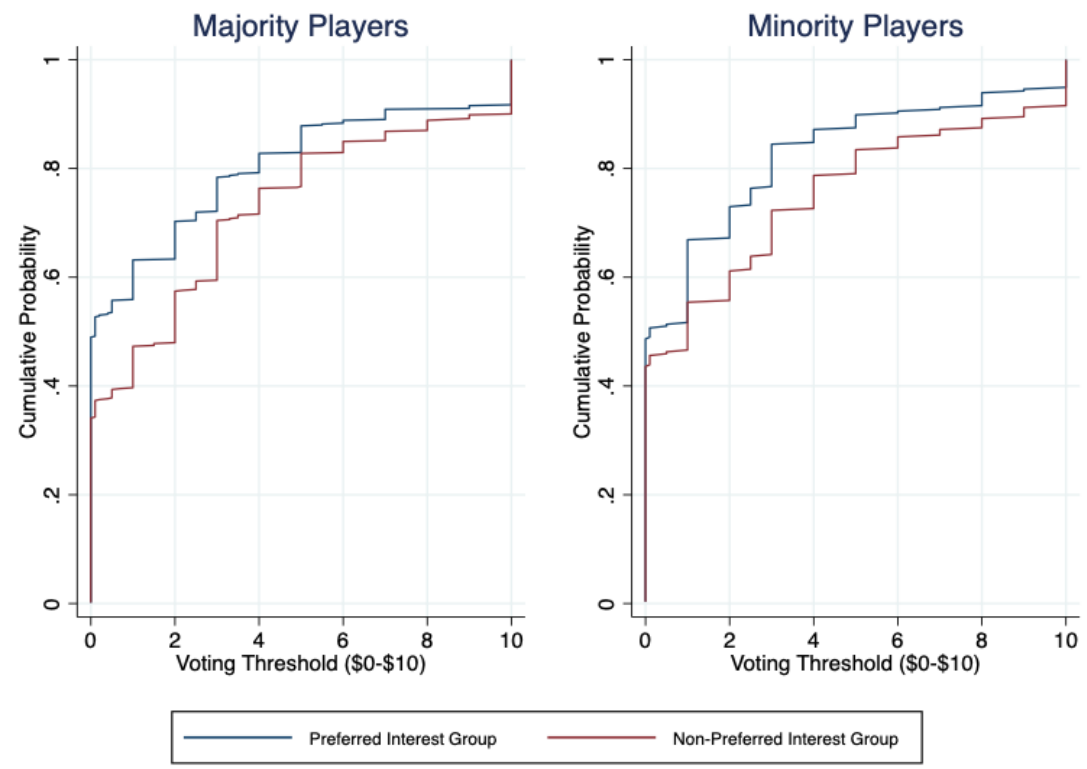

Notes: This figure displays cumulative distribution functions of individuals' voting thresholds for the Policy \& Budget Treatment majority and minority peak subjects.

Table A2 presents regression results corresponding to Figure 2 in the text.

Table A2: Logit Results: Policy Choice by Majority Minority Status

\begin{tabular}{ccccc}
\hline \hline In Ideological Majority & $1.89^{* * *}$ & $1.89^{* * *}$ & $1.90^{* * *}$ & $1.94^{* * *}$ \\
& $(0.24)$ & $(0.29)$ & $(0.29)$ & $(0.31)$ \\
Equilibrium Prediction: Choose Own & -0.18 & -0.18 & -0.15 & -0.08 \\
& $(0.47)$ & $(0.41)$ & $(0.42)$ & $(0.40)$ \\
Number of Observations & 444 & 444 & 444 & 444 \\
\hline Clustered Std. Errors & & Yes & Yes & Yes \\
Period Fixed Effects & & & Yes & Yes \\
Session Fixed Effects & & & & Yes \\
\hline \hline
\end{tabular}

$$
{ }^{*} \mathrm{p}<0.1,{ }^{* *} \mathrm{p}<0.05,{ }^{* * *} \mathrm{p}<0.01
$$

Notes: This table shows how being in the committee majority (versus minority) and being predicted to choose one's own policy (all majority players, and a portion of minority players) affect a subject's likelihood of choosing their preferred policy. 
Tables A3 (self-allocation amount by majority/minority status) and A4 (partner allocation by partner type, majority players only) present regression results corresponding to Figure 3.

\begin{tabular}{ccccc} 
Table A3: Self-Allocation Amount by & Majority Minority Status \\
\hline \hline In Ideological Majority & -0.35 & -0.35 & -0.35 & -0.35 \\
& $(0.25)$ & $(0.30)$ & $(0.28)$ & $(0.27)$ \\
Number of Observations & 444 & 444 & 444 & 444 \\
\hline Clustered Std. Errors & & Yes & Yes & Yes \\
Period Fixed Effects & & Yes & Yes \\
Session Fixed Effects & & Yes \\
\hline \hline & \\
\hline & & &
\end{tabular}

Notes: This table shows how being in the committee majority (versus minority) affects a subject's self-allocated amount of the budget.

Table A4: Allocation Amount to Partners by Partner Type (Majority Players Only)

\begin{tabular}{ccccc}
\hline \hline Other Majority Partner & $0.76^{* * *}$ & $0.76^{* * *}$ & $0.76^{* * *}$ & $0.76^{* * *}$ \\
& $(0.14)$ & $(0.18)$ & $(0.18)$ & $(0.18)$ \\
Number of Observations & 592 & 592 & 592 & 592 \\
\hline Clustered Std. Errors & & Yes & Yes & Yes \\
Period Fixed Effects & & Yes & Yes \\
Session Fixed Effects & & & Yes \\
\hline \hline & & &
\end{tabular}

Notes: This table shows, for majority subjects, how partner type (majority versus minority) affects partner allocation amounts.

\subsection{Hypothesis 3: Status Quo Proposer Advantage}

The first four columns of Table A5 present regression results corresponding to Figure 4. The second four columns conduct the same exercise as 4 but substituting self-allocated amount for policy choice. 
Table A5: Policy Choice and Self-Allocation Amount by Status Quo Location

\begin{tabular}{|c|c|c|c|c|c|c|c|c|}
\hline \multirow{4}{*}{ Status Quo Preferred } & \multicolumn{4}{|c|}{ Dep Var: Policy Choice } & \multicolumn{4}{|c|}{ Dep Var: Self-Allocation } \\
\hline & (1) & $(2)$ & (3) & (4) & (5) & $(6)$ & $(7)$ & (8) \\
\hline & $0.41^{* *}$ & $0.41^{* *}$ & $0.52^{* *}$ & $0.51^{* *}$ & 0.05 & 0.05 & -0.49 & $-0.54^{*}$ \\
\hline & $(0.20)$ & $(0.20)$ & $(0.23)$ & $(0.24)$ & $(0.24)$ & $(0.27)$ & $(0.31)$ & $(0.30)$ \\
\hline Observations & 444 & 444 & 444 & 444 & 444 & 444 & 444 & 444 \\
\hline Clustered & & Yes & Yes & Yes & & Yes & Yes & Yes \\
\hline Period Fixed Effects & & & Yes & Yes & & & Yes & Yes \\
\hline Session Fixed Effects & & & & Yes & & & & Yes \\
\hline
\end{tabular}

Notes: This table shows how status quo policy location affects a subject's likelihood of choosing their preferred policy (columns 1-4, logistic regression) and their self-allocated amount (columns 5-8, OLS regression).

\subsection{Hypothesis 5: Trade-offs and Policy Compromise}

Table A6 presents regression results corresponding to Figure 5.

Table A6: Logit Results: Policy Choice by Treatment (Policy \& Budget v. Policy Only),

\begin{tabular}{ccccc}
\multicolumn{5}{c}{ Majority/Minority Status } \\
\hline \hline In Ideological Majority & $-1.85^{* * *}$ & $-1.85^{* * *}$ & $-1.88^{* * *}$ & $-1.93^{* * *}$ \\
& $(0.22)$ & $(0.27)$ & $(0.28)$ & $(0,29)$ \\
Policy Only Treatment & $0.85^{* * *}$ & $0.85^{* * *}$ & $0.88^{* * *}$ & $0.21^{* * *}$ \\
& $(0.24)$ & $(0.31)$ & $(0.31)$ & $(0.56)$ \\
Minority $\times$ Policy Only & $1.02^{* * *}$ & $1.02^{* *}$ & $1.03^{* *}$ & $1.04^{* *}$ \\
& $(0.38)$ & $(0.47)$ & $(0.47)$ & $(0.48)$ \\
Number of Observations & 726 & 726 & 726 & 726 \\
\hline Clustered Std. Errors & & Yes & Yes & Yes \\
Period Fixed Effects & & Yes & Yes \\
Session Fixed Effects & & & Yes \\
\hline \hline & ${ }^{*} \mathrm{p}<0.1,{ }^{* *} \mathrm{p}<0.05,{ }^{* * *} \mathrm{p}<0.01$ &
\end{tabular}

Notes: This table shows, how being in the committee majority (versus minority) and being in the Policy Only Treatment versus the Policy \& Budget Treatment affect a subject's likelihood of choosing their preferred policy. 


\subsection{Hypothesis 6: Voting Thresholds Between Treatments}

Table A7 presents regression results showing that voting thresholds are on average smaller in the Policy \& Budget Treatment than in the Budget Only and Budget Only No Information Treatments.

Table A7: Voting Thresholds by Treatment (Policy \& Budget, Budget Only, Budget

\begin{tabular}{ccccc}
\multicolumn{5}{c}{ Only No Information $)$} \\
\hline \hline Budget Only & $0.67^{* * *}$ & $0.67^{* *}$ & $0.67^{* *}$ & 0.25 \\
& $(0.13)$ & $(0.26)$ & $(0.26)$ & $(0.59)$ \\
Budget Only No Information & $0.73^{* * *}$ & $0.73^{* *}$ & $0.73^{* *}$ & $1.39^{* *}$ \\
& $(0.15)$ & $(0.28)$ & $(0.28)$ & $(0.57)$ \\
Number of Observations & 1,776 & 1,776 & 1,775 & 1,776 \\
\hline Clustered Std. Errors & & Yes & Yes & Yes \\
Period Fixed Effects & & & Yes & Yes \\
Session Fixed Effects & & & Yes \\
\hline \hline
\end{tabular}

Notes: This table shows how being in the Budget Only and Budget Only No Information Treatments versus the Policy \& Budget Treatment affects subjects' voting thresholds. In the Budget Only Treatments, subjects stated thresholds for a budget division only; we compare thresholds in these Treatments to subjects' thresholds for preferred interest groups in the Policy \& Budget Treatment.

\subsection{Hypothesis 7: One-way Splits, Minimum Winning Coali- tions}

Table A8 reproduces Figure 7 (columns 1-4) and also considers as an outcome the proposal of a minimal winning coalition (MWC) (columns 5-8). 
Table A8: One-way Splits and Minimal Winning Coalitions by Treatment (Policy \& Budget, Budget Only, and Budget Only No Information)

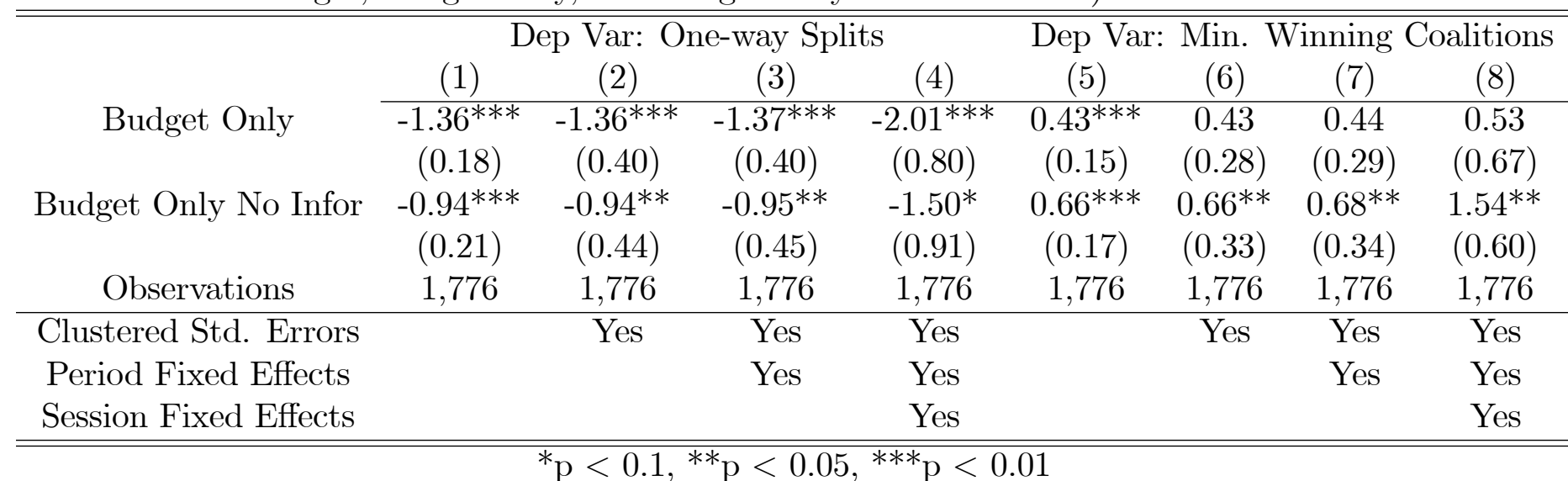

Notes: This table shows how treatment assignment (Budget Only or Budget Only No Information versus Policy \& Budget) affects a subject's likelihood of proposing a one-way split (columns 1-4, logistic regression) and a minimal winning coalition (columns 5-8, logistic regression).

We conjectured, based on previous evidence in the extant literature, that MWCs regarding the budgetary split would be modal in all Treatments with a budget division. To facilitate comparison between Treatments, we defined a MWC as a sharing of the budget between two people only. ${ }^{1}$ Table A 8 indicates that the likelihood that subjects propose a MWC is significantly higher in the Budget Only No Information Treatment as compared with the Policy \& Budget Treatment, but differences between the Budget Only and Policy \& Budget Treatments (and between the two Budget Only Treatments) are not statistically distinguishable from zero.

Our finding regarding the low proportion of MWCs, especially in the Budget Only Treatments, is surprising. A recent meta-analysis reports that 66 percent of all allocations in 3-player Baron and Ferejohn (1989) experiments involve sharing the fund among two players only (Baranski and Morton, 2020). These experiments allow for multiple rounds

\footnotetext{
${ }^{1}$ In the Policy \& Budget Treatment, a player could keep all the money and compromise on the policy with another player. While we categorize this proposal as a one-way split, utility is certainly split two ways.
} 
of bargaining until approval and subjects vote for a proposal upon observing it, unlike our treatments.

Could it be that displaying political ideological preferences affects the proportion of MWCs? A recent Baron and Ferejohn experiment (Laroze, Hugh-Jones, and Leininger, 2020) reports no statistically significant difference in the likelihood of 2-way splits between baseline and a treatment where self-reported political ideology was displayed to subjects. This is in line with our findings as we find no significant difference between the two Budget Only Treatments.

What policy are subjects choosing when they keep all the budget? $72 \%$ of minority members that keep all the budget choose a policy different than their preferred one (compromising with the majority) while only half of the majority members proposing to keep all the budget choose an alternative policy.

\subsection{Hypothesis 8: Agreement Rates}

Table A9 presents results regressing agreement rates on an indicator variable for whether a subject was randomly assigned to a treatment where information political preferences was shared (Policy \& Budget, Policy Only, and Budget Only Treatments) or not (Budget Only No Information and Induced Policy \& Budget Treatments).

Table A9: Agreement Rates by Whether Political Preference Information was Shared

\begin{tabular}{ccccc}
\hline \hline Treatments with Information & $0.58^{* * *}$ & $0.58^{* * *}$ & $0.58^{* * *}$ & 0.40 \\
& $(0.11)$ & $(0.15)$ & $(0.15)$ & $(0.50)$ \\
Number of Observations & 2,712 & 2,712 & 2,712 & 2,712 \\
\hline Clustered Std. Errors & & Yes & Yes & Yes \\
Period Fixed Effects & & Yes & Yes \\
Session Fixed Effects & & & Yes \\
\hline \hline & & &
\end{tabular}

Notes: This table shows how assignment to a treatment where information on political preferences was shared (Policy \& Budget, Policy Only, and Budget Only Treatments) versus where information was not shared (Budget Only No Information and Induced Policy \& Budget Treatments) affects proposal acceptance rates. 


\subsection{Hypothesis 9: Elicited Preferences and Voting Behavior}

Table A10 below corresponds to Figure 8 .

Table A10: Correlation between elicited preferences and voting behavior

\begin{tabular}{|c|c|c|c|c|c|c|c|c|}
\hline & (1) & $(2)$ & $(3)$ & $\overline{(4)}$ & $(5)$ & $(6)$ & $(7)$ & $(8)$ \\
\hline Min. Accepted Amount & $\begin{array}{c}0.64^{* *} \\
(0.04)\end{array}$ & $\begin{array}{c}0.64^{* * *} \\
(0.08)\end{array}$ & $\begin{array}{c}0.63^{* * *} \\
(0.08)\end{array}$ & $\begin{array}{c}.62^{* * *} \\
(0.07)\end{array}$ & $\begin{array}{c}0.68^{* * *} \\
(0.05)\end{array}$ & $\begin{array}{c}0.68^{* * *} \\
(0.10)\end{array}$ & $\begin{array}{c}0.67^{* * *} \\
(0.10)\end{array}$ & $\begin{array}{c}0.66^{* * *} \\
(0.10)\end{array}$ \\
\hline Induced Preferences & & & & & $\begin{array}{c}2.30^{* * *} \\
(0.16)\end{array}$ & $\begin{array}{c}2.30^{* * *} \\
(0.39)\end{array}$ & $\begin{array}{c}2.30^{* * *} \\
(0.39)\end{array}$ & $\begin{array}{c}3.20^{* * *} \\
(0.70)\end{array}$ \\
\hline MAA $\times$ Induced Pref & & & & & $\begin{array}{c}-0.11 \\
(0.07)\end{array}$ & $\begin{array}{l}-0.11 \\
(0.15)\end{array}$ & $\begin{array}{l}-0.11 \\
(0.15)\end{array}$ & $\begin{array}{l}-0.10 \\
(0.15)\end{array}$ \\
\hline Observations & 2,544 & 2,544 & 2,544 & 2,544 & 2,544 & 2,544 & 2,544 & 2,544 \\
\hline Clustered Std. Errors & & Yes & Yes & Yes & & Yes & Yes & Yes \\
\hline Period Fixed Effects & & & Yes & Yes & & & Yes & Yes \\
\hline Session Fixed Effects & & & & Yes & & & & Yes \\
\hline
\end{tabular}

Notes: This table shows how elicited minimum acceptable amounts (MAAs) correlate with stated voting thresholds, as well as the interaction between MAA and treatment assignment (induced preferences versus naturally-occurring preferences).

Did using behaviorally elicited as opposed to stated political preferences affect results? Subjects' partisan identification and political ideology were measured on 7-point discrete scales whereas our revealed measure of political preferences is on a continuous scale, making comparison difficult under the current design. However, recent research suggests that behavioral elicitation methods will more clearly distinguish "strong" partisans and politically active individuals from weaker partisans and more politically disengaged respondents where non-behavioral elicitation methods might not (Haas and Morton, 2018).

Figure A7 maps stated political party identification and ideology against subjects' elicited peak preferences (preference direction) and minimum acceptable amounts (preference intensity), averaged across the four topic areas, to bring additional evidence to bear on elicited preferences - and, in this case, how they compare to stated preferences, as opposed to voting behavior. The figure shows that there is a relationship between 
stated and elicited preferences - subjects who say they hold strong partisan affiliations and ideologies state higher MAAs on average, and subjects who say they are further right/conservative (left/liberal) on the political spectrum are more likely to choose right (left) political interest groups as their peak.

Figure A7: Comparing Stated and Elicited Preferences

(a) Comparing with Self Reported Party Identification

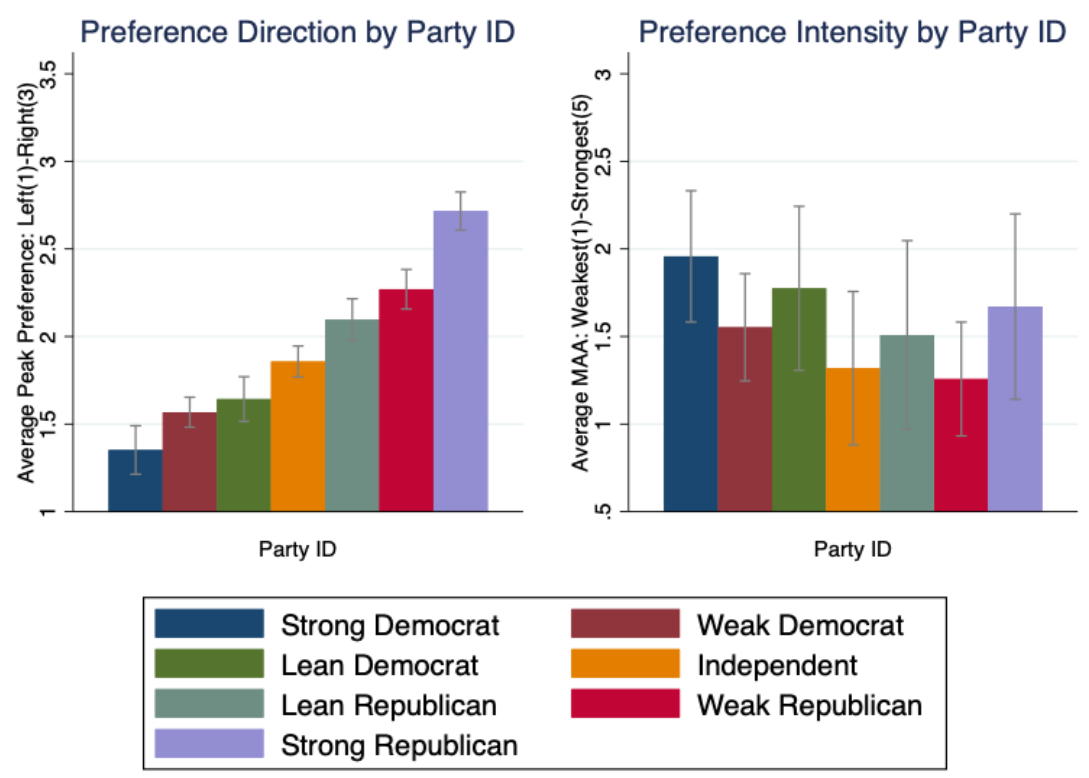


(b) Comparing with Self-Reported Ideology

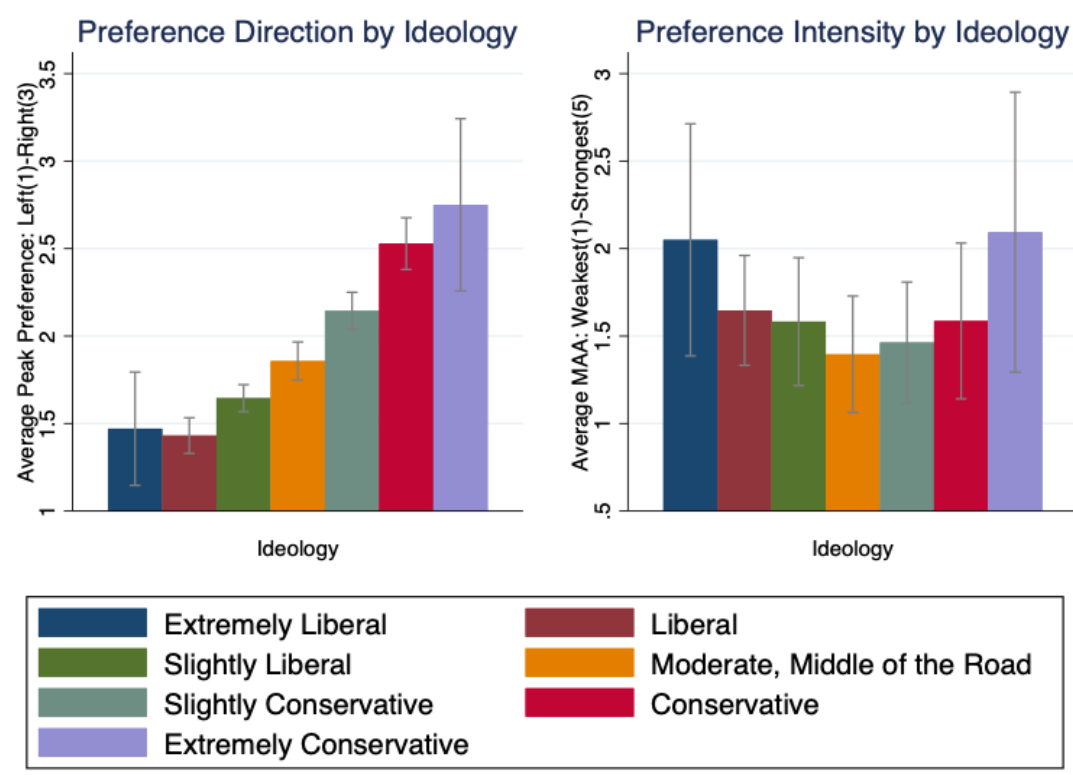

Further, we can see that differences between weak/lean Democrats and Republicans become smaller in magnitude under our behavioral measure, potentially consistent with the behavioral method better distinguishing fervent from less fervent partisans and holders of ideologies (Haas and Morton, 2018). Politically independent respondents have the lowest preference strength under our behavioral measure, which may be consistent with findings going back to Campbell et al. (1980) that independent voters are comparatively more disengaged. Importantly, we only observe this shrinkage in differences between weak/strong partisans and holders of ideologies in preference strength and not in preference direction, where there was no cost to expressing one's preferred interest group and thus where the method of elicitation should have less of an effect on measured political preferences.

\subsection{Hypothesis 10: Induced v. Elicited Preferences}

Figure A8 replicates Figure A5 (elicited preferences) for the Induced Policy \& Budget Treatment. 
Figure A8: Voting Thresholds by Non-Preferred Interest Group Type (Induced)
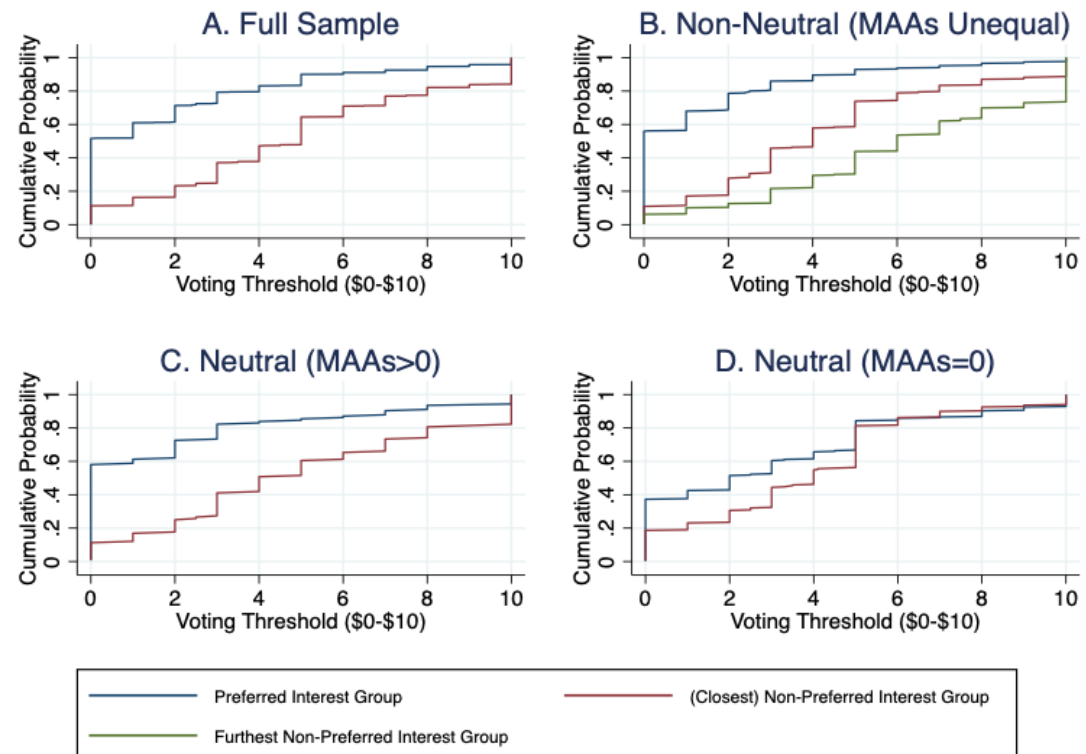

(Closest) Non-Preferred Interest Group

Notes: This figure displays cumulative distribution functions of individuals' voting thresholds for all subjects in the Induced Policy \& Budget Treatment (panel A), only those subjects who stated unequal MAAs for non-preferred groups (panel B), only those subjects who stated equal non-zero MAAs for both non-preferred groups (panel C), or only those subjects who stated equal MAAs of $\$ 0$ for both non-preferred groups (panel D). Voting thresholds are shown for preferred versus non-preferred interest groups or, in the case where subjects felt differently about the two alternative interest groups (panel B), thresholds for the preferred and the least and second least preferred groups.

\section{Sample Demographics}


Demographic Summary Statistics: by Treatment Assignment

\begin{tabular}{|c|c|c|c|c|c|c|c|c|c|c|c|c|}
\hline & \multicolumn{12}{|c|}{ Treatment Assignment } \\
\hline & \multicolumn{2}{|c|}{$\begin{array}{c}\text { Policy \& } \\
\text { Budget }\end{array}$} & \multicolumn{2}{|c|}{$\begin{array}{l}\text { Budget } \\
\text { Only }\end{array}$} & \multicolumn{2}{|c|}{$\begin{array}{l}\text { Policy } \\
\text { Only }\end{array}$} & \multicolumn{2}{|c|}{$\begin{array}{l}\text { Budget Only } \\
\text { No Info }\end{array}$} & \multicolumn{2}{|c|}{$\begin{array}{c}\text { Induced Policy } \\
\& \text { Budget }\end{array}$} & \multicolumn{2}{|c|}{ Total } \\
\hline & $\mathrm{N}$ & $\%$ & $\mathrm{~N}$ & $\%$ & $\mathrm{~N}$ & $\%$ & $\mathrm{~N}$ & $\%$ & $\mathrm{~N}$ & $\%$ & $\mathrm{~N}$ & $\%$ \\
\hline \multicolumn{13}{|l|}{ Gender } \\
\hline Male & 47 & 52.2 & 51 & 58.6 & 24 & 50.0 & 26 & 57.8 & 43 & 62.3 & 191 & 56.3 \\
\hline Female & 43 & 47.8 & 34 & 39.1 & 24 & 50.0 & 19 & 42.2 & 26 & 37.7 & 146 & 43.1 \\
\hline Non-Binary/Third Gender & 0 & 0.0 & 2 & 2.3 & 0 & 0.0 & 0 & 0.0 & 0 & 0.0 & 2 & 0.6 \\
\hline Total & 90 & 100.0 & 87 & 100.0 & 48 & 100.0 & 45 & 100.0 & 69 & 100.0 & 339 & 100.0 \\
\hline \multicolumn{13}{|l|}{ Partisan Identification } \\
\hline Strong Democrat & 15 & 16.7 & 17 & 19.5 & 8 & 16.7 & 9 & 20.0 & 7 & 10.1 & 56 & 16.5 \\
\hline Weak Democrat & 17 & 18.9 & 22 & 25.3 & 12 & 25.0 & 8 & 17.8 & 9 & 13.0 & 68 & 20.1 \\
\hline Lean Democrat & 9 & 10.0 & 12 & 13.8 & 3 & 6.2 & 4 & 8.9 & 14 & 20.3 & 42 & 12.4 \\
\hline Independent & 16 & 17.8 & 7 & 8.0 & 3 & 6.2 & 9 & 20.0 & 12 & 17.4 & 47 & 13.9 \\
\hline Lean Republican & 9 & 10.0 & 9 & 10.3 & 5 & 10.4 & 3 & 6.7 & 7 & 10.1 & 33 & 9.7 \\
\hline Weak Republican & 14 & 15.6 & 16 & 18.4 & 14 & 29.2 & 7 & 15.6 & 13 & 18.8 & 64 & 18.9 \\
\hline Strong Republican & 10 & 11.1 & 4 & 4.6 & 3 & 6.2 & 5 & 11.1 & 7 & 10.1 & 29 & 8.6 \\
\hline Total & 90 & 100.0 & 87 & 100.0 & 48 & 100.0 & 45 & 100.0 & 69 & 100.0 & 339 & 100.0 \\
\hline \multicolumn{13}{|l|}{ Ideology } \\
\hline Extremely Liberal & 5 & 5.6 & 8 & 9.2 & 3 & 6.2 & 1 & 2.2 & 2 & 2.9 & 19 & 5.6 \\
\hline Liberal & 12 & 13.3 & 23 & 26.4 & 9 & 18.8 & 14 & 31.1 & 9 & 13.0 & 67 & 19.8 \\
\hline Slightly Liberal & 22 & 24.4 & 18 & 20.7 & 4 & 8.3 & 6 & 13.3 & 15 & 21.7 & 65 & 19.2 \\
\hline Moderate, Middle of the Road & 21 & 23.3 & 12 & 13.8 & 13 & 27.1 & 10 & 22.2 & 22 & 31.9 & 78 & 23.0 \\
\hline Slightly Conservative & 16 & 17.8 & 17 & 19.5 & 11 & 22.9 & 8 & 17.8 & 11 & 15.9 & 63 & 18.6 \\
\hline Conservative & 14 & 15.6 & 8 & 9.2 & 8 & 16.7 & 5 & 11.1 & 10 & 14.5 & 45 & 13.3 \\
\hline Extremely Conservative & 0 & 0.0 & 1 & 1.1 & 0 & 0.0 & 1 & 2.2 & 0 & 0.0 & 2 & 0.6 \\
\hline Total & 90 & 100.0 & 87 & 100.0 & 48 & 100.0 & 45 & 100.0 & 69 & 100.0 & 339 & 100.0 \\
\hline \multicolumn{13}{|l|}{ Ethnicity } \\
\hline White & 62 & 68.9 & 68 & 78.2 & 37 & 77.1 & 28 & 62.2 & 48 & 69.6 & 243 & 71.7 \\
\hline Black & 4 & 4.4 & 6 & 6.9 & 4 & 8.3 & 3 & 6.7 & 4 & 5.8 & 21 & 6.2 \\
\hline Hispanic & 4 & 4.4 & 2 & 2.3 & 0 & 0.0 & 2 & 4.4 & 0 & 0.0 & 8 & 2.4 \\
\hline Asian & 20 & 22.2 & 9 & 10.3 & 6 & 12.5 & 12 & 26.7 & 16 & 23.2 & 63 & 18.6 \\
\hline Other & 0 & 0.0 & 2 & 2.3 & 1 & 2.1 & 0 & 0.0 & 1 & 1.4 & 4 & 1.2 \\
\hline Total & 90 & 100.0 & 87 & 100.0 & 48 & 100.0 & 45 & 100.0 & 69 & 100.0 & 339 & 100.0 \\
\hline \multicolumn{13}{|l|}{ Annual Family Income } \\
\hline Less than $\$ 25,000$ & 4 & 4.4 & 4 & 4.6 & 1 & 2.1 & 1 & 2.2 & 2 & 2.9 & 12 & 3.5 \\
\hline$\$ 25,000-\$ 35,000$ & 9 & 10.0 & 4 & 4.6 & 1 & 2.1 & 2 & 4.4 & 4 & 5.8 & 20 & 5.9 \\
\hline$\$ 35,000-\$ 50,000$ & 11 & 12.2 & 8 & 9.2 & 2 & 4.2 & 4 & 8.9 & 4 & 5.8 & 29 & 8.6 \\
\hline$\$ 50,000-\$ 75,000$ & 11 & 12.2 & 7 & 8.0 & 3 & 6.2 & 4 & 8.9 & 5 & 7.2 & 30 & 8.8 \\
\hline$\$ 75,000-\$ 100,000$ & 13 & 14.4 & 10 & 11.5 & 3 & 6.2 & 7 & 15.6 & 13 & 18.8 & 46 & 13.6 \\
\hline$\$ 100,000-\$ 150,000$ & 14 & 15.6 & 24 & 27.6 & 11 & 22.9 & 7 & 15.6 & 11 & 15.9 & 67 & 19.8 \\
\hline$\$ 150,000-\$ 250,000$ & 14 & 15.6 & 18 & 20.7 & 17 & 35.4 & 16 & 35.6 & 19 & 27.5 & 84 & 24.8 \\
\hline$\$ 250,000-\$ 500,000$ & 13 & 14.4 & 5 & 5.7 & 7 & 14.6 & 2 & 4.4 & 9 & 13.0 & 36 & 10.6 \\
\hline$\$ 500,000-\$ 1$ million & 1 & 1.1 & 5 & 5.7 & 2 & 4.2 & 1 & 2.2 & 1 & 1.4 & 10 & 2.9 \\
\hline Over $\$ 1$ million & 0 & 0.0 & 2 & 2.3 & 1 & 2.1 & 1 & 2.2 & 1 & 1.4 & 5 & 1.5 \\
\hline Total & 90 & 100.0 & 87 & 100.0 & 48 & 100.0 & 45 & 100.0 & 69 & 100.0 & 339 & 100.0 \\
\hline \multicolumn{13}{|l|}{ Religion } \\
\hline Jewish & 2 & 2.2 & 10 & 11.5 & 1 & 2.1 & 1 & 2.2 & 5 & 7.2 & 19 & 5.6 \\
\hline Muslim & 1 & 1.1 & 0 & 0.0 & 0 & 0.0 & 1 & 2.2 & 0 & 0.0 & 2 & 0.6 \\
\hline Buddhist & 0 & 0.0 & 0 & 0.0 & 0 & 0.0 & 2 & 4.4 & 0 & 0.0 & 2 & 0.6 \\
\hline Hindu & 1 & 1.1 & 2 & 2.3 & 0 & 0.0 & 1 & 2.2 & 3 & 4.3 & 7 & 2.1 \\
\hline Atheist & 8 & 8.9 & 6 & 6.9 & 4 & 8.3 & 2 & 4.4 & 2 & 2.9 & 22 & 6.5 \\
\hline Protestant & 10 & 11.1 & 12 & 13.8 & 9 & 18.8 & 7 & 15.6 & 7 & 10.1 & 45 & 13.3 \\
\hline Roman Catholic & 26 & 28.9 & 25 & 28.7 & 15 & 31.2 & 10 & 22.2 & 18 & 26.1 & 94 & 27.7 \\
\hline Mormon & 0 & 0.0 & 0 & 0.0 & 0 & 0.0 & 1 & 2.2 & 0 & 0.0 & 1 & 0.3 \\
\hline Eastern or Greek Orthodox & 0 & 0.0 & 0 & 0.0 & 0 & 0.0 & 0 & 0.0 & 2 & 2.9 & 2 & 0.6 \\
\hline Agnostic & 10 & 11.1 & 5 & 5.7 & 3 & 6.2 & 4 & 8.9 & 3 & 4.3 & 25 & 7.4 \\
\hline Nothing in particular & 22 & 24.4 & 21 & 24.1 & 10 & 20.8 & 10 & 22.2 & 21 & 30.4 & 84 & 24.8 \\
\hline Something Else & 10 & 11.1 & 6 & 6.9 & 6 & 12.5 & 6 & 13.3 & 8 & 11.6 & 36 & 10.6 \\
\hline Total & 90 & 100.0 & 87 & 100.0 & 48 & 100.0 & 45 & 100.0 & 69 & 100.0 & 339 & 100.0 \\
\hline
\end{tabular}


Additional Demographic Summary Statistics: by Treatment Assignment

\begin{tabular}{|c|c|c|c|c|c|c|c|c|c|c|c|c|}
\hline & \multicolumn{12}{|c|}{ Treatment Assignment } \\
\hline & \multicolumn{2}{|c|}{$\begin{array}{c}\text { Policy \& } \\
\text { Budget }\end{array}$} & \multicolumn{2}{|c|}{$\begin{array}{l}\text { Budget } \\
\text { Only }\end{array}$} & \multicolumn{2}{|c|}{$\begin{array}{l}\text { Policy } \\
\text { Only }\end{array}$} & \multicolumn{2}{|c|}{$\begin{array}{l}\text { Budget Only } \\
\text { No Info }\end{array}$} & \multicolumn{2}{|c|}{$\begin{array}{c}\text { Induced Policy } \\
\text { \& Budget }\end{array}$} & \multicolumn{2}{|c|}{ Total } \\
\hline & $\mathrm{N}$ & $\%$ & $\mathrm{~N}$ & $\%$ & $\mathrm{~N}$ & $\%$ & $\mathrm{~N}$ & $\%$ & $\mathrm{~N}$ & $\%$ & $\mathrm{~N}$ & $\%$ \\
\hline \multicolumn{13}{|l|}{ Educational Attainment } \\
\hline Freshman & 24 & 26.7 & 19 & 21.8 & 12 & 25.0 & 5 & 11.1 & 12 & 17.4 & 72 & 21.2 \\
\hline Sophomore & 7 & 7.8 & 15 & 17.2 & 9 & 18.8 & 7 & 15.6 & 22 & 31.9 & 60 & 17.7 \\
\hline Junior & 14 & 15.6 & 21 & 24.1 & 10 & 20.8 & 18 & 40.0 & 13 & 18.8 & 76 & 22.4 \\
\hline Senior & 34 & 37.8 & 25 & 28.7 & 14 & 29.2 & 13 & 28.9 & 19 & 27.5 & 105 & 31.0 \\
\hline Graduate Student & 11 & 12.2 & 7 & 8.0 & 3 & 6.2 & 2 & 4.4 & 3 & 4.3 & 26 & 7.7 \\
\hline Total & 90 & 100.0 & 87 & 100.0 & 48 & 100.0 & 45 & 100.0 & 69 & 100.0 & 339 & 100.0 \\
\hline \multicolumn{13}{|l|}{ Evangelical } \\
\hline No & 81 & 90.0 & 79 & 90.8 & 41 & 85.4 & 40 & 88.9 & 64 & 92.8 & 305 & 90.0 \\
\hline Yes & 9 & 10.0 & 8 & 9.2 & 7 & 14.6 & 5 & 11.1 & 5 & 7.2 & 34 & 10.0 \\
\hline Total & 90 & 100.0 & 87 & 100.0 & 48 & 100.0 & 45 & 100.0 & 69 & 100.0 & 339 & 100.0 \\
\hline \multicolumn{13}{|l|}{ Religiosity } \\
\hline Not at all important & 27 & 30.0 & 31 & 35.6 & 13 & 27.1 & 7 & 15.6 & 14 & 20.3 & 92 & 27.1 \\
\hline Not too important & 24 & 26.7 & 25 & 28.7 & 11 & 22.9 & 15 & 33.3 & 29 & 42.0 & 104 & 30.7 \\
\hline Somewhat important & 31 & 34.4 & 21 & 24.1 & 16 & 33.3 & 16 & 35.6 & 20 & 29.0 & 104 & 30.7 \\
\hline Very important & 8 & 8.9 & 10 & 11.5 & 8 & 16.7 & 7 & 15.6 & 6 & 8.7 & 39 & 11.5 \\
\hline Total & 90 & 100.0 & 87 & 100.0 & 48 & 100.0 & 45 & 100.0 & 69 & 100.0 & 339 & 100.0 \\
\hline Age (avg.) & 90 & 21.4 & 87 & 20.6 & 48 & 21.0 & 45 & 21.2 & 69 & 20.46 & 339 & 20.91 \\
\hline \multicolumn{13}{|l|}{ From Ohio } \\
\hline No & 30 & 33.3 & 39 & 44.8 & 17 & 35.4 & 13 & 28.9 & 28 & 40.6 & 127 & 37.5 \\
\hline Yes & 60 & 66.7 & 48 & 55.2 & 31 & 64.6 & 32 & 71.1 & 41 & 59.4 & 212 & 62.5 \\
\hline Total & 90 & 100.0 & 87 & 100.0 & 48 & 100.0 & 45 & 100.0 & 69 & 100.0 & 339 & 100.0 \\
\hline \multicolumn{13}{|l|}{ Foreign Student } \\
\hline No & 81 & 90.0 & 79 & 90.8 & 45 & 93.8 & 42 & 93.3 & 63 & 91.3 & 310 & 91.4 \\
\hline Yes & 9 & 10.0 & 8 & 9.2 & 3 & 6.2 & 3 & 6.7 & 6 & 8.7 & 29 & 8.6 \\
\hline Total & 90 & 100.0 & 87 & 100.0 & 48 & 100.0 & 45 & 100.0 & 69 & 100.0 & 339 & 100.0 \\
\hline \multicolumn{13}{|l|}{ Interest in Politics } \\
\hline None & 2 & 2.2 & 1 & 1.1 & 1 & 2.1 & 1 & 2.2 & 5 & 7.2 & 10 & 2.9 \\
\hline Very little & 14 & 15.6 & 22 & 25.3 & 9 & 18.8 & 8 & 17.8 & 18 & 26.1 & 71 & 20.9 \\
\hline Some & 43 & 47.8 & 34 & 39.1 & 27 & 56.2 & 22 & 48.9 & 20 & 29.0 & 146 & 43.1 \\
\hline Quite a bit & 18 & 20.0 & 17 & 19.5 & 9 & 18.8 & 10 & 22.2 & 19 & 27.5 & 73 & 21.5 \\
\hline A great deal & 13 & 14.4 & 13 & 14.9 & 2 & 4.2 & 4 & 8.9 & 7 & 10.1 & 39 & 11.5 \\
\hline Total & 90 & 100.0 & 87 & 100.0 & 48 & 100.0 & 45 & 100.0 & 69 & 100.0 & 339 & 100.0 \\
\hline \multicolumn{13}{|l|}{ Discuss Politics } \\
\hline Not at all & 3 & 3.3 & 3 & 3.4 & 2 & 4.2 & 4 & 8.9 & 9 & 13.0 & 21 & 6.2 \\
\hline Very little & 21 & 23.3 & 23 & 26.4 & 17 & 35.4 & 10 & 22.2 & 15 & 21.7 & 86 & 25.4 \\
\hline Some & 41 & 45.6 & 32 & 36.8 & 16 & 33.3 & 16 & 35.6 & 28 & 40.6 & 133 & 39.2 \\
\hline Quite a bit & 17 & 18.9 & 24 & 27.6 & 11 & 22.9 & 12 & 26.7 & 12 & 17.4 & 76 & 22.4 \\
\hline A great deal & 8 & 8.9 & 5 & 5.7 & 2 & 4.2 & 3 & 6.7 & 5 & 7.2 & 23 & 6.8 \\
\hline Total & 90 & 100.0 & 87 & 100.0 & 48 & 100.0 & 45 & 100.0 & 69 & 100.0 & 339 & 100.0 \\
\hline Political Knowledge & & & & & & & & & & & & \\
\hline Not at all & 1 & 1.1 & 3 & 3.4 & 0 & 0.0 & 0 & 0.0 & 3 & 4.3 & 7 & 2.1 \\
\hline Very little & 20 & 22.2 & 16 & 18.4 & 11 & 22.9 & 9 & 20.0 & 15 & 21.7 & 71 & 20.9 \\
\hline Some & 40 & 44.4 & 38 & 43.7 & 26 & 54.2 & 21 & 46.7 & 29 & 42.0 & 154 & 45.4 \\
\hline Quite a bit & 21 & 23.3 & 22 & 25.3 & 9 & 18.8 & 13 & 28.9 & 16 & 23.2 & 81 & 23.9 \\
\hline A great deal & 8 & 8.9 & 8 & 9.2 & 2 & 4.2 & 2 & 4.4 & 6 & 8.7 & 26 & 7.7 \\
\hline Total & 90 & 100.0 & 87 & 100.0 & 48 & 100.0 & 45 & 100.0 & 69 & 100.0 & 339 & 100.0 \\
\hline Follow Politics & & & & & & & & & & & & \\
\hline Not at all & 4 & 4.4 & 2 & 2.3 & 1 & 2.1 & 1 & 2.2 & 5 & 7.2 & 13 & 3.8 \\
\hline Very little & 21 & 23.3 & 22 & 25.3 & 10 & 20.8 & 13 & 28.9 & 18 & 26.1 & 84 & 24.8 \\
\hline Some & 36 & 40.0 & 31 & 35.6 & 25 & 52.1 & 19 & 42.2 & 25 & 36.2 & 136 & 40.1 \\
\hline Quite a bit & 19 & 21.1 & 21 & 24.1 & 10 & 20.8 & 10 & 22.2 & 17 & 24.6 & 77 & 22.7 \\
\hline A great deal & 10 & 11.1 & 11 & 12.6 & 2 & 4.2 & 2 & 4.4 & 4 & 5.8 & 29 & 8.6 \\
\hline Total & 90 & 100.0 & 87 & 100.0 & 48 & 100.0 & 45 & 100.0 & 69 & 100.0 & 339 & 100.0 \\
\hline
\end{tabular}

